\title{
Downdrafts and the Evolution of Boundary Layer Thermodynamics in Hurricane Earl (2010) before and during Rapid Intensification
}

\author{
JOSHUA B. WADLER \\ Rosenstiel School of Marine and Atmospheric Science, University of Miami, Miami, Florida \\ JUN A. ZHANG \\ NOAA/Atlantic Oceanographic and Meteorological Laboratory/Hurricane Research Division, and \\ Cooperative Institute for Marine and Atmospheric Studies, University of Miami, Miami, Florida \\ BENJAMIN JAIMES AND LYNN K. SHAY \\ Rosenstiel School of Marine and Atmospheric Science, University of Miami, Miami, Florida
}

(Manuscript received 15 March 2018, in final form 9 August 2018)

\begin{abstract}
Using a combination of NOAA P-3 aircraft tail Doppler radar, NOAA and NASA dropsondes, and buoyand drifter-based sea surface temperature data, different types of downdrafts and their influence on boundary layer (BL) thermodynamics are examined in Hurricane Earl (2010) during periods prior to rapid intensification [RI; a 30-kt $\left(15.4 \mathrm{~m} \mathrm{~s}^{-1}\right)$ increase in intensity over $24 \mathrm{~h}$ ] and during RI. Before RI, the BL was generally warm and moist. The largest hindrances for intensification are convectively driven downdrafts inside the radius of maximum winds (RMW) and upshear-right quadrant, and vortex-tilt-induced downdrafts outside the RMW in the upshear-left quadrant. Possible mechanisms for overcoming the low entropy $\left(\theta_{e}\right)$ air induced by these downdrafts are BL recovery through air-sea enthalpy fluxes and turbulent mixing by atmospheric eddies. During RI, convective downdrafts of varying strengths in the upshear-left quadrant had differing effects on the low-level entropy and surface heat fluxes. Interestingly, the stronger downdrafts corresponded with maximums in $10-\mathrm{m} \theta_{e}$. It is hypothesized that the large amount of evaporation in a strong $\left(>2 \mathrm{~m} \mathrm{~s}^{-1}\right)$ downdraft underneath a precipitation core can lead to high amounts of near-surface specific humidity. By contrast, weaker downdrafts corresponded with minimums in $10-\mathrm{m} \theta_{e}$, likely because they contained lower evaporation rates. Since weak and dry downdrafts require more surface fluxes to recover the low entropy air than strong and moist downdrafts, they are greater hindrances to storm intensification. This study emphasizes how different types of downdrafts are tied to hurricane intensity change through their modification of BL thermodynamics.
\end{abstract}

\section{Introduction}

Tropical Cyclone (TC) Earl (2010) was a heavily sampled storm in the western Atlantic basin that formed on 25 August 2010 and dissipated on 5 September 2010. The mechanisms for Earl's intensity evolution are examined in multiple studies. Rogers et al. (2015) and Stevenson et al. (2014) found that when Earl was a tropical storm, the vortex was significantly misaligned. They hypothesized that deep convection on the east side of the storm helped to vertically align the vortex so rapid intensification (RI; greater than 30-kt increase in

Corresponding author: Joshua Wadler, jwadler@rsmas.miami.edu intensity over $24 \mathrm{~h}$ ) could occur. During Earl's RI, the vertical shear lessened and convection remained inside the radius of maximum winds (RMW), maximizing the efficiency of intensification. Susca-Lopata et al. (2015) also did a case study of Hurricane Earl, but noted that during RI deep convection was preferentially located outside of the $2-\mathrm{km}$ altitude RMW, but inside the $8-\mathrm{km}$ altitude RMW.

Montgomery et al. (2014) studied the spinup dynamics of Hurricane Earl and found that during RI, a strong inflow layer advected angular momentum surfaces into an eyewall region that contained supergradient winds. Jaimes et al. (2015) also studied the role of lowlevel processes, with a focus on air-sea interaction. They 
noted that the moisture disequilibrium near the surface dominated the enthalpy flux calculations, especially as the storm went over an oceanic warm eddy feature, arguing that surface enthalpy fluxes supplied a sufficient amount of energy for Earl to undergo RI.

What has not been studied using observations from Earl is the detailed relationship between the convective processes, boundary layer (BL) thermodynamics, and air-sea interaction, all in a framework related to TC intensity change. The present study aims to provide an additional explanation for Earl's intensity evolution by analyzing the effect of downdrafts on BL thermodynamics, especially in the inner core. We use dropsonde profiles from NOAA and NASA aircraft, in combination with NOAA WP-3D (P-3) tail Doppler radar analyses, and buoy and drifter based sea surface temperature (SST) data to understand how the BL thermodynamic evolution influences its intensity. This analysis is complimentary to the previous studies on Hurricane Earl, as we analyze how the storm underwent RI, utilizing the positive effects of deep convection, angular momentum advection, and warm oceanic features, while overcoming the negative influences of downdrafts.

Downdrafts excited by evaporation of a precipitation core are mentioned in previous studies (e.g., Riemer et al. 2010; Tang and Emanuel 2010, 2012; Molinari et al. 2013). Riemer et al. (2010) explored these downdrafts by imposing vertical shear on a mature TC. They found that vortex-scale downdrafts caused by the vortex tilt occur underneath precipitation cores and flux a significant amount of low equivalent potential temperature ( $\theta_{e}$; also referred to as moist entropy) air into the BL. The low $\theta_{e}$ air (termed "anti-fuel") spiraled toward the center of the storm from larger radii and reduced eyewall entropy. Similar results were reached by Tang and Emanuel (2012), who found that advecting low $\theta_{e}$ environmental air into the inflow layer through downdrafts is the most efficient way for it to weaken the TC circulation.

Vortex-scale downdrafts from upper-level convergence usually occur on the upshear side of the TC (e.g., Reasor et al. 2013; DeHart et al. 2014). These broad downdrafts limit the presence and strength of upshear deep convection (e.g., Black et al. 1994; DeMaria 1996; Reasor et al. 2000; Frank and Ritchie 2001; Corbosiero and Molinari 2002, 2003; Black et al. 2002; Reasor and Eastin 2012; Rogers et al. 2015; Wadler et al. 2018). The upshear region also often contains the lowest BL $\theta_{e}$, determined from a composite dropsonde database (Zhang et al. 2013).

Many case studies have observed downdrafts advecting low $\theta_{e}$ air into the TC BL (e.g., Barnes et al. 1983;
Powell 1990; Barnes and Powell 1995; Didlake and Houze 2009; Eastin et al. 2012; Barnes and Dolling 2013; Molinari et al. 2013; Dolling and Barnes 2014; Zhang et al. 2017). Two recent case studies highlight the negative impacts that this low $\theta_{e}$ air can have on TC intensity. In Tropical Cyclones Bertha and Cristobal (2014), Nguyen et al. (2017) showed that precipitation symmetry was hindered by convective downdrafts, broad subsidence upshear, and advection of dry air into the upshear quadrants. In Hurricane Edouard (2014), Zawislak et al. (2016) and Rogers et al. (2016) showed that downdrafts in the upshear quadrants, and specifically the upshear-right (USR) quadrant, hindered the humidification of those quadrants, even during RI. Though these studies do not explicitly examine the effect of individual downdrafts, they highlight how downdrafts can hinder precipitation symmetry and perturb BL thermodynamics.

There are two leading scenarios for how downdraftinduced low $\theta_{e}$ air impacts TC intensity. First, if low $\theta_{e}$ air is advected into the eyewall, it reduces the amount of work that is done through the Carnot cycle (Emanuel 1986; Tang and Emanuel 2010; Riemer et al. 2010). Second, if low $\theta_{e}$ air is advected around the storm into the downshear-right (DSR) quadrant, it inhibits the development of new convection (Zhang et al. 2013, 2017). In either case, it is possible for the low $\theta_{e}$ air to recover before impacting the storm's intensity. The amount of recovery is, in part, a function of the upperocean thermal structure, as spatial variability of the airsea enthalpy fluxes is influenced by mesoscale oceanic features. For instance, TCs over warm-core oceanic eddies have significantly higher air-sea enthalpy fluxes than over a background oceanic state (Shay et al. 2000; Shay and Uhlhorn 2008; Jaimes et al. 2016).

This study describes the evolution of BL thermodynamics in Hurricane Earl before and during RI. Specifically, we examine how different types of downdrafts influence the BL thermal structure and how the storm overcame the negative impacts of downdrafts on Earl's intensification. The following are the objectives of this paper:

1) Document, through the use of in situ observations, low $\theta_{e}$ air entering the $\mathrm{BL}$ from convective and vortex tilt-driven downdrafts and determine their implications on intensity change;

2) Evaluate the differing effects of inner-core moist and dry downdrafts;

3) Examine the role of air-sea enthalpy fluxes and atmospheric turbulent eddies in boundary layer recovery of $\theta_{e}$ before and during Earl's rapid intensification. 


\section{Data and methodology}

Two periods during Hurricane Earl's life cycle are analyzed in this study (Fig. 1). Period 1 (hereafter referred to as P1) spanned from 1800 UTC 28 August to 0600 UTC 29 August 2010, ending as Earl began to undergo RI. During P1, Earl was tropical storm strength with an average intensity of $\sim 25 \mathrm{~m} \mathrm{~s}^{-1}$. Period 2 (hereafter referred to as P2) spanned from 1800 UTC 29 August to 0600 UTC 30 August 2010. During this period, Earl was undergoing RI with an average intensity of $\sim 45 \mathrm{~m} \mathrm{~s}^{-1}$, a category 2 hurricane.

\section{a. Radar data}

The radar data presented are X-Band tail Doppler radar analyses from the NOAA P-3 aircraft. The raw radar data are postprocessed using a variational algorithm that is described in Gamache (1997) and solves the Doppler projection and continuity equation to project onto a grid that has a $2-\mathrm{km}$ horizontal resolution and a 0.5-km vertical resolution (Reasor et al. 2009). Each flight is broken down into swaths, which consist of an eye penetration and a downwind leg. The swaths are commonly used to analyze processes on the mesoscale (e.g., Rogers et al. 2013a; Reasor et al. 2013; Rogers et al. 2015; Wadler et al. 2018).

The P-3 flight during P1 contains three swaths while the flight during P2 contains four swaths. For each period, all of the swaths are averaged together to create a merged analysis (Reasor et al. 2013). The merged analyses are commonly used for describing large-scale storm structure, but can smooth convective and mesoscale features in locations where swaths overlap (e.g., in the inner core). For assessing storm-scale structures, all of the swaths in the merged analysis assume the same storm center.

Radial cross sections were taken through the radar swaths at dropsonde points of interest (DPoIs; described in the section 2c). The cross sections are from $20 \mathrm{~km}$ radially inward to $20 \mathrm{~km}$ radially outward from the dropsonde splash location. Although the dropsondes only measure thermodynamic features in the lower parts of the atmosphere, the radar cross sections extend to $16-\mathrm{km}$ altitude to highlight potential origins for characteristics seen in the BL. To account for data coverage constraints, the cross sections were averaged $4 \mathrm{~km}$ upwind and downwind. This is similar to the technique used by Wadler et al. (2018) to identify characteristics of convective bursts (see Fig. 2 in that paper).

\section{b. SST data}

SST data were obtained from the U.S. Global Ocean Data Assimilation Experiment (http://www.usgodae.org/).

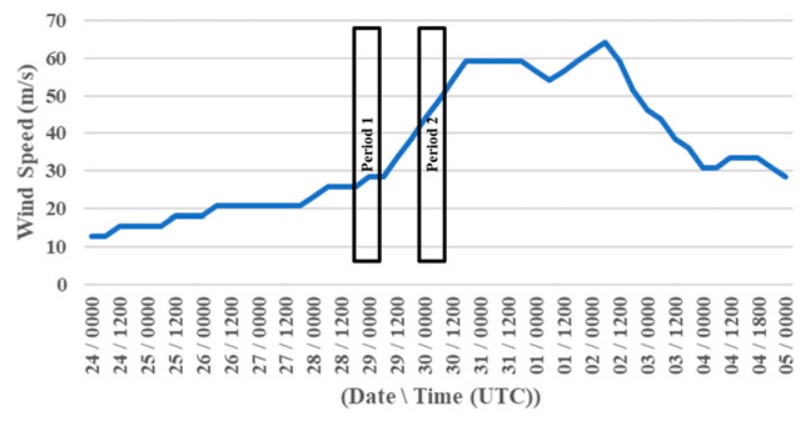

FIG. 1. A time series of Hurricane Earl's best track intensity from its early identification to dissipation. The two periods identified in this study (before rapid intensification, period 1; and continuing rapid intensification, period 2) are outlined.

The data originate from fixed and drifting surface weather buoys, including some underneath the inner core of Earl. To collocate the dropsonde and irregular SST measurements, the SST data were interpolated with a scheme based on Mariano and Brown (1992). For a further description of how the SST data were collected and processed refer to Jaimes et al. (2015).

While it is ideal to have collocated SST and dropsonde measurements for air-sea enthalpy flux calculations (e.g., Zhang et al. 2017), the cross-storm variability in SST during the two time periods are order $0.1^{\circ} \mathrm{C}$. Additionally, Earl moved over oceanic regimes with high levels of upper ocean heat content (OHC; relative to the $26^{\circ} \mathrm{C}$ isotherm depth), where SST cooling was less than $0.5^{\circ} \mathrm{C}$ during storm passage (Meyers et al. 2014; Jaimes et al. 2015). The overall temperature bias between actual (irregular SST data points) and interpolated SST structures was $-0.03^{\circ} \mathrm{C}$ with a standard deviation of $0.29^{\circ} \mathrm{C}$. The correlation coefficient was 0.99 . Thus, the error associated with the interpolation technique is negligible (Jaimes et al. 2015).

The horizontal contour plots of SST, along with airsea enthalpy fluxes and all other 10-m variables, were interpolated with a triangulation-based natural neighbor scheme. This technique is continuous and preserves the original dropsonde measured/collocated SST values. Note that the horizontal plots of the derived fields (Figs. 3, 7, 8, 9, and 13) are only utilized for a gross view of BL thermodynamic characteristics and the BL recovery calculation shown in the appendix.

\section{c. Dropsonde data}

As detailed by Montgomery et al. (2014), one NOAA P-3 aircraft was flown into Earl during P1, and collected data from 21 dropsondes within $250 \mathrm{~km}$ of the storm center. During P2, 4 aircrafts (P-3, DC-8, C-130, and G-IV) flew into Earl, releasing 48 dropsondes. The 
(a)

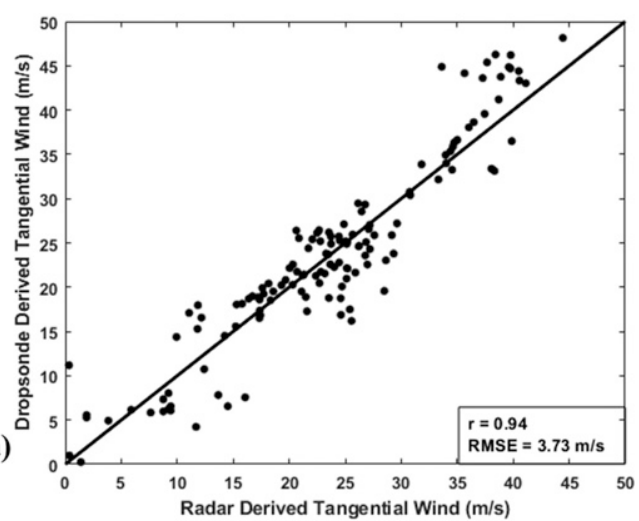

(c)

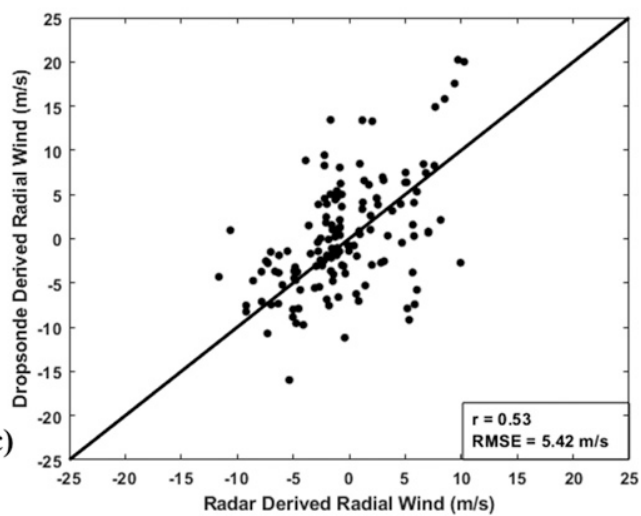

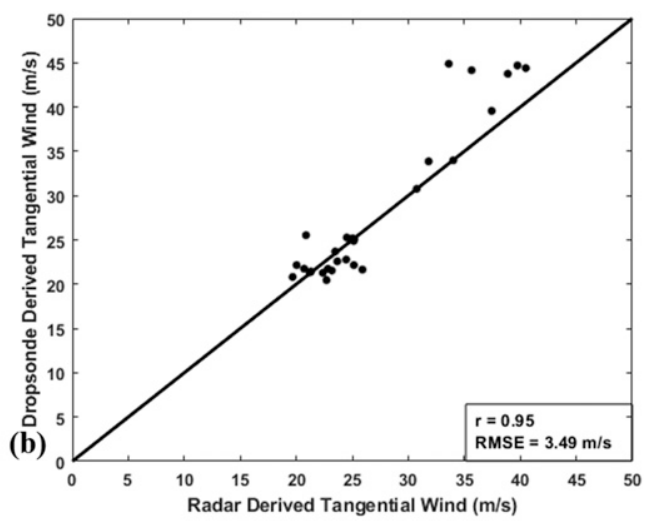

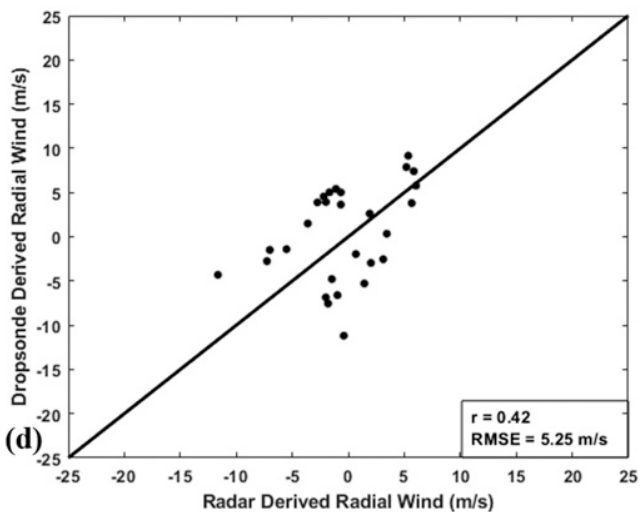

FIG. 2. Comparison between measurements made by Doppler radar analyses and dropsondes of (a) tangential wind for all dropsondes, (b) tangential wind for DPoIs, (c) radial wind for all dropsondes, and (d) radial wind for DPoIs. The one-to-one line is shown in each plot.

sampling was part of collaborations between the NOAA Hurricane Field Program (Rogers et al. 2013b) and the NASA Genesis and Rapid Intensification Processes (GRIP; Braun et al. 2013) experiment. Since this study compares dropsonde and radar data, it only includes dropsondes released while the P-3 was sampling. The dropsonde measures a quasi-vertical profile of wind speed, wind direction, temperature, and humidity with vertical resolution of $\sim 7 \mathrm{~m}$. A detailed description on dropsonde observations can be found in Hock and Franklin (1999). The raw data were postprocessed using NCAR's ASPEN software. To plot the data in stormrelative coordinates, the storm center was determined by P-3 center fixes and best track, following the method of Willoughby and Chelmow (1982).

The dropsondes were vertically interpolated for every $10 \mathrm{~m}$ in the lowest $3 \mathrm{~km}$. Air temperature and specific humidity were used to calculate $\theta_{e}$ using the method of Bolton (1980). Combining the 10-m dropsondemeasured quantities with the SST data described in section $2 \mathrm{~b}$, latent heat flux $\left(Q_{l}\right)$ and sensible heat flux $\left(Q_{s}\right)$ were calculated using Eqs. (1) and (2), respectively:

$$
\begin{aligned}
& Q_{l}=\rho_{a} c_{p} C_{h} U_{10}\left(\mathrm{SST}-T_{a}\right), \\
& Q_{s}=\rho_{a} L_{v} C_{e} U_{10}\left(q_{s}-q_{a}\right),
\end{aligned}
$$

where $\rho_{a}$ is the density of dry air; $C_{h}=C_{e}=1.1 \times 10^{-3}$ are the exchange coefficients for sensible heat and latent heat fluxes, respectively (values from Zhang et al. 2008a); $c_{p}=1004 \mathrm{~J} \mathrm{~kg}^{-1} \mathrm{~K}^{-1}$ is the specific heat of dry air at constant pressure; $L_{v}=2.5 \times 10^{6} \mathrm{~J} \mathrm{~kg}^{-1}$ is the latent heat of evaporation; $T_{a}$ and SST are the 10-m air and sea surface temperature, respectively; and $q_{a}$ and $q_{s}$ are the 10-m and sea surface specific humidity, respectively. The combined latent heat and sensible heat flux is referred to as the air-sea heat (enthalpy) fluxes.

A few dropsonde profiles had missing 10-m wind speed data. To rectify this, multiple data fitting schemes were tested on profiles with complete data coverage. Linear fitting of the lowest $100-\mathrm{m}$ data was the most stable scheme and had a $10-\mathrm{m}$ wind speed root-meansquare error (RMSE) of $0.92 \mathrm{~m} \mathrm{~s}^{-1}$. Therefore, for profiles with at least 5 data points in the lowest $100 \mathrm{~m}$, the 10-m wind speed was estimated with a best-fit line. The 
TABLE 1. A summary of the location of all the DPoIs identified in this study. Here $r^{*}$ is the radial location relative to the $2-\mathrm{km}$ RMW (i.e., $r^{*}=R / \mathrm{RMW}_{2 \mathrm{KM}}$ ).

\begin{tabular}{ccc}
\hline $\begin{array}{c}\text { Dropsonde point } \\
\text { of interest (DPoI) }\end{array}$ & Period & Location \\
\hline A & 1 & $r^{*} \sim 0.9$ in USR quadrant \\
B & 1 & $r^{*} \sim 1.5$ in USL quadrant \\
C & 1 & $r^{*} \sim 1.9$ in DSL quadrant \\
D & 2 & $r^{*} \sim 0.8$ in border between DSL \\
& & and USL quadrant \\
E & 2 & $r^{*} \sim 0.8$ in USL quadrant \\
F & 2 & $r^{*} \sim 0.9$ in border between USL \\
& & and USR quadrants \\
G & 2 & $r^{*} \sim 1.8$ in USL quadrant \\
H & 2 & $r^{*} \sim 0.8$ in DSR quadrant \\
\hline
\end{tabular}

extrapolation of low-level wind speeds introduces uncertainty, but is necessary to complete the analysis. A total of 19 dropsondes needed extrapolation (out of 69 total dropsondes in this study), but a majority $(>80 \%)$ were only missing the $10-\mathrm{m}$ value.

DPoIs are locations that are discussed in detail throughout the manuscript. They were constructed by taking radial cross sections through the radar swaths at dropsonde splash locations (described in section 2a). The goal was to relate the thermodynamic features found in the dropsonde profiles to the dynamical characteristics seen in the radar analyses. At DPoIs covered by multiple radar swaths (three instances), the cross sections were taken through the swath closest in time to the dropsonde splash. To focus on strong vertical motions, radar cross sections with vertical velocities that did not exceed $1.5 \mathrm{~m} \mathrm{~s}^{-1}$ were eliminated. A list of DPoIs is given in Table 1 along with a description of their location.

Uncertainty arises since the radar analyses are temporally averaged quantities from multiple radar sweeps, while the dropsonde measurements are closer to instantaneous. To evaluate whether the dropsondes are measuring the same features as the Doppler radar analyses, the tangential wind (Fig. 2a) and radial wind (Fig. 2c) from the two platforms were statistically compared. The GPS location of the dropsonde at each Doppler radar analyses height (500-m resolution) was used to compute its storm-relative location. For these comparisons, the dropsonde-measured velocities were averaged $250 \mathrm{~m}$ above and below the analyses height to minimize the effects of vertical resolution differences, though the instantaneous measurements from the dropsonde yielded similar results (not shown). The RMSEs between the Doppler radar and dropsondederived tangential wind and radial wind are 3.73 and $5.42 \mathrm{~m} \mathrm{~s}^{-1}$, respectively. The subset of dropsondes sampling the DPoIs, the focus of this study, has RMSEs of 3.49 and $5.25 \mathrm{~m} \mathrm{~s}^{-1}$ for tangential wind (Fig. 2b) and radial wind (Fig. 2d), respectively. The RMSEs are comparable to those from previous studies comparing wind velocities from two measurement platforms (e.g., Reasor et al. 2009; Klotz and Uhlhorn 2014), yielding confidence that the dropsonde profiles and radar analyses are sampling the same wind features.

It is important to note that only vertical velocity from the Doppler radar swaths is shown in this study. The Doppler radar-measured vertical velocity has been verified against flight-level data in other TCs (e.g., Reasor et al. 2009; Rogers et al. 2012). On the other hand, there is relatively large uncertainty in the postprocessed vertical velocity from dropsondes, since it is an estimated quantity based on the difference between the total dropsonde fall rate and a theoretical terminal fall speed (Hock and Franklin 1999). The resulting vertical velocities from the dropsonde measurements have not been statistically validated against other measurement platforms over a wide range of wind speeds. To the authors' knowledge, Stern et al. (2016) is the only study that utilized the dropsonde-measured vertical velocities to study TC structure. While Stern et al. analyzed the distribution of extreme updrafts, they pointed out that the uncertainty in the coefficients used in the terminal fall speed equation can lead to errors of a few percent in the vertical velocity estimates. Thus, we only use Doppler radar-measured vertical velocity to quantify the strengths of downdrafts in Hurricane Earl.

\section{Results}

A summary of the environmental conditions during each period is given in Table 2. During P1 and P2, Earl's

TABLE 2. A summary of TC Earl's intensity and characteristics as well as the oceanic and atmospheric environmental conditions during the two time periods identified in this study.

\begin{tabular}{ccccccc}
\hline \hline & & Vertical shear & & Distance between \\
Period (flight ID) & $\begin{array}{c}\text { km RMW } \\
(\mathrm{km})\end{array}$ & $\begin{array}{c}\text { Vertical shear } \\
\text { magnitude (kt) }\end{array}$ & $\begin{array}{c}\text { heading (degrees } \\
\text { CCW from east) }\end{array}$ & $\begin{array}{c}\text { NHC best track } \\
\text { velocity }\left(\mathrm{m} \mathrm{s}^{-1}\right)\end{array}$ & $\begin{array}{c}\text { Inner-core } \\
\text { SST }\left({ }^{\circ} \mathrm{C}\right)\end{array}$ & $\begin{array}{c}\text { MPI and best track } \\
\left.\text { winds (m s }{ }^{-1}\right)\end{array}$ \\
\hline 1 (100828I1) & 65 & 18.1 & 223 & 28.3 & 29.5 & 49.4 \\
$2(100829 \mathrm{I} 1)$ & 49 & 9 & 205 & 43.7 & 30.0 & 30.4 \\
\hline
\end{tabular}


(a)
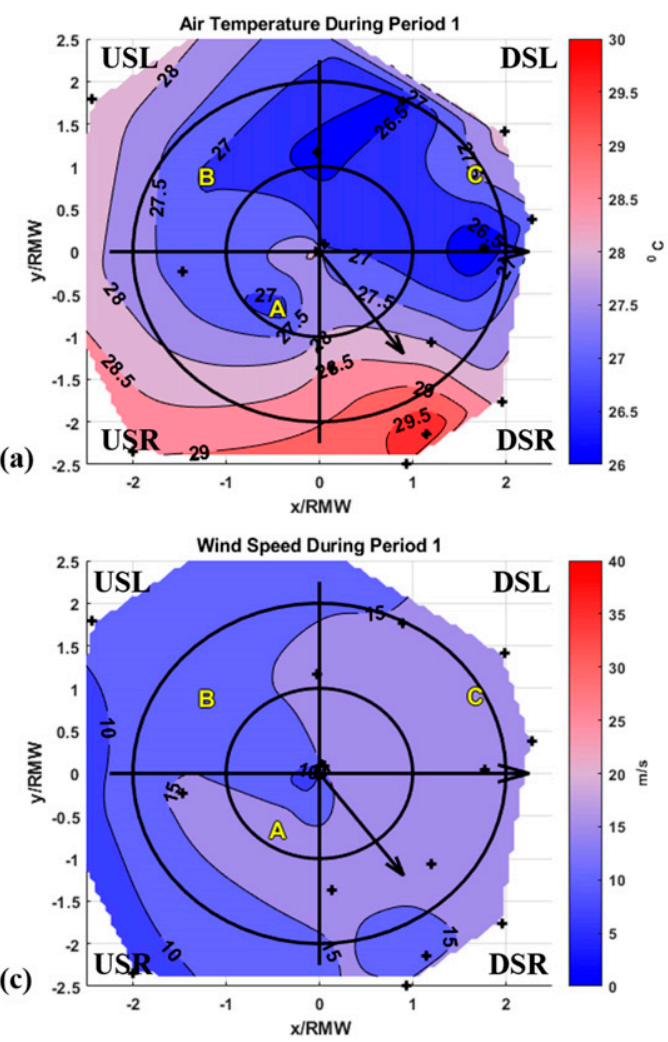

(b)
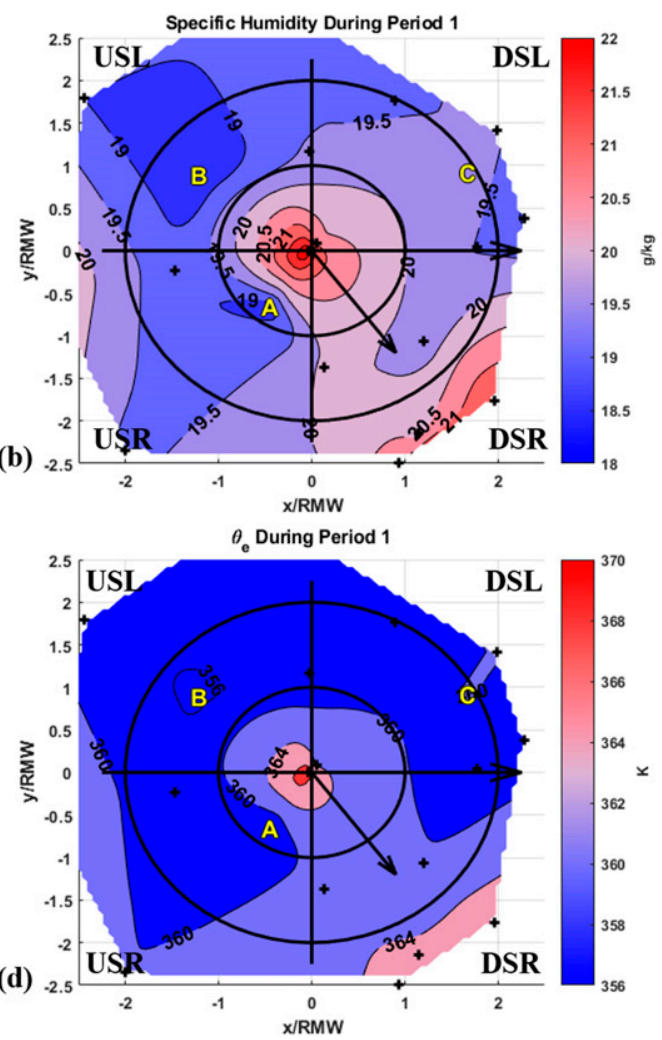

FIG. 3. (a) Normalized radial and shear-rotated (pointing to the right) 10-m air temperature; (b) 10-m specific humidity; (c) 10-m wind speed; (d) 10-m $\theta_{e}$ during period 1 . DPoIs A, B, and C are outlined with a "+ " representing dropsondes not considered DPoIs. Storm motion is indicated by the short black arrow, and radial bands of $r^{*}=1$ and $r^{*}=2$ are overlaid. The contouring intervals are (a) $0.5^{\circ} \mathrm{C}$, (b) $0.5 \mathrm{~g} \mathrm{~kg}^{-1}$, (c) $5 \mathrm{~m} \mathrm{~s}^{-1}$, and (d) $4 \mathrm{~K}$.

Doppler radar-derived 2-km altitude RMW was 65 and $49 \mathrm{~km}$, respectively. During both periods, dry air associated with the Saharan air layer was in Earl's vicinity (i.e., greater than $200 \mathrm{~km}$ from storm center), but was not significantly entrained into the circulation (Braun et al. 2013). The environmental wind shear, derived from the Statistical Hurricane Intensity Prediction Scheme (SHIPS; DeMaria and Kaplan 1999) database, went from 18.1 to $9 \mathrm{kt}$ and rotated clockwise by $15^{\circ}$. The small change in shear direction allows for an equal comparison of the shear's effect on Earl's internal dynamics (Cione et al. 2013).

All the environmental factors indicate more favorable conditions for intensification during $\mathrm{P} 2$. To isolate the effects of internal dynamics, the analysis is done in normalized radial $r^{*}\left(r^{*}=R / \mathrm{RMW}_{2 \mathrm{KM}}\right)$ and shearoriented coordinates (shear vector pointing to the right). During both periods, Earl was at least $30 \mathrm{~m} \mathrm{~s}^{-1}$ away from its maximum potential intensity (Emanuel 1988) from the SHIPS database, meaning that Earl had the thermodynamic potential to strengthen and that internal dynamics were important to the intensification process.

\section{a. Period 1: Prior to RI}

The 10-m temperature was largest in the DSR quadrant (Fig. 3a). The other three quadrants maintain a fairly uniform temperature distribution within the RMW, but with a local minimum below $27^{\circ} \mathrm{C}$ in the USR quadrant (DPoI A). The 10-m specific humidity has similar characteristics (Fig. 3b). Values inside the RMW exceed $19 \mathrm{~g} \mathrm{~kg}^{-1}$ in all quadrants, with the most moisture in the DSR quadrant. Together, this makes an asymmetric near-surface $\theta_{e}$ distribution (Fig. 3d). The $\theta_{e}$ in the DSR quadrant exceeds $360 \mathrm{~K}$ at all radii, while other quadrants maintain $\sim 360 \mathrm{~K}$ at the RMW. The stormrelative wind speed (Fig. 3c) also has an asymmetric structure, with wind speeds at the RMW generally less than $15 \mathrm{~m} \mathrm{~s}^{-1}$ in the upshear-left (USL) quadrant and greater than $15 \mathrm{~m} \mathrm{~s}^{-1}$ elsewhere.

Since the sampling period was hours before Earl began undergoing RI, there can only be a few hindrances to its intensification. At DPoI A, a relatively weak downdraft of $\sim 1.5 \mathrm{~m} \mathrm{~s}^{-1}$ extends into the $\mathrm{BL}$, and is maximized at $\sim 4.5-\mathrm{km}$ altitude and $\sim 5 \mathrm{~km}$ radially inward 

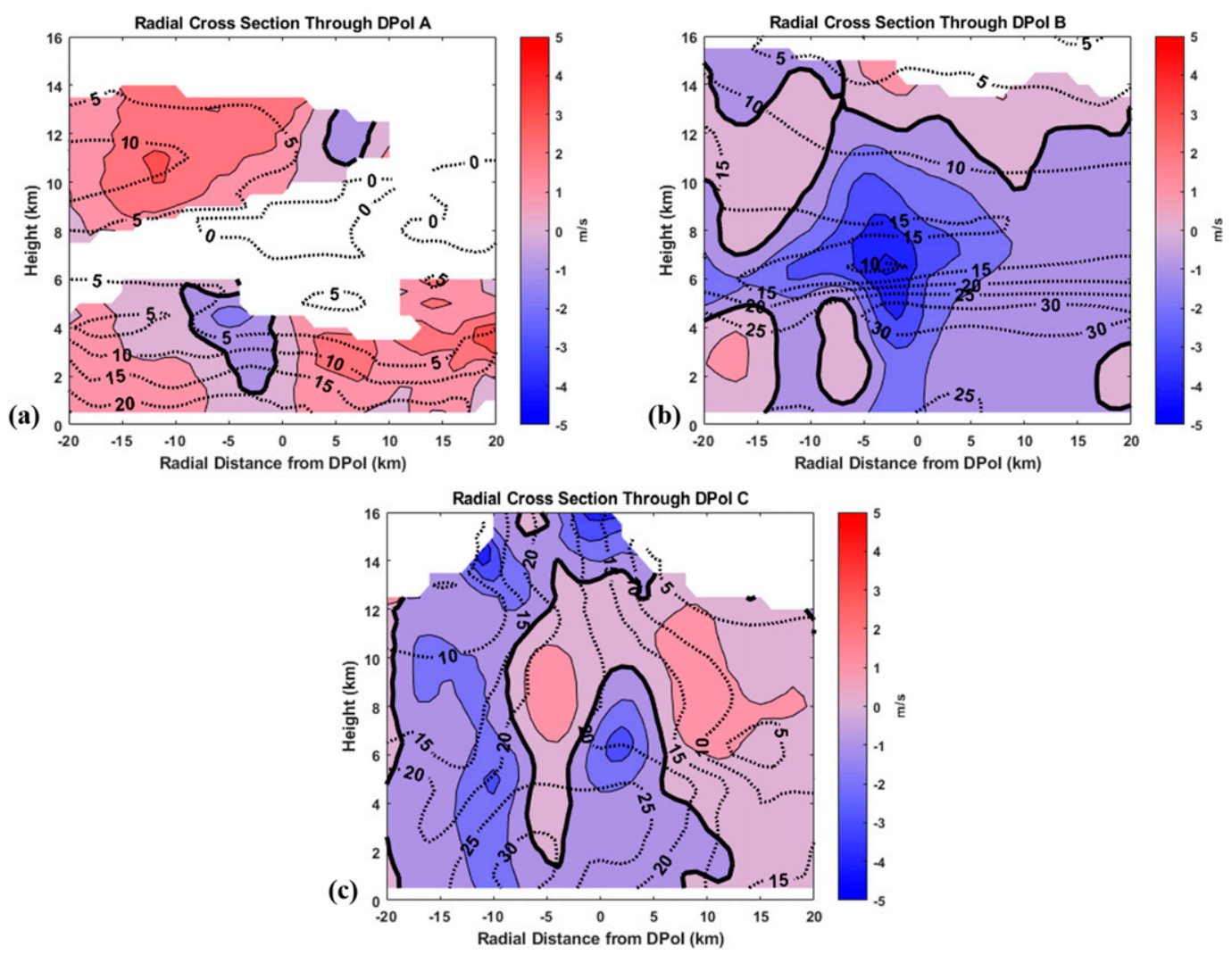

FIG. 4. Radial cross sections of Doppler radar-derived vertical velocity at splash locations of (a) DPoI A, (b) DPoI B, and (c) DPoI C. The shading is vertical velocity at contouring intervals of $1.0 \mathrm{~m} \mathrm{~s}^{-1}$. The zero-vertical velocity line is in boldface. Reflectivity is contoured at $5-\mathrm{dBZ}$ intervals with dashed contours.

of the dropsonde splash location (Fig. 4a). This downdraft is below an updraft that is maximized at $\sim 10-\mathrm{km}$ altitude, and is also in the vicinity of a low-level updraft $\sim 2 \mathrm{~km}$ radially outward of the DPoI. These features are also observed on the storm-scale merged analyses (Figs. 5a-c). At all altitudes, the downdraft is centered near DPoI A and is surrounded by weak updrafts. Note that in each panel, the dropsonde position is based on its $10-\mathrm{m}$ altitude. The average horizontal displacement in the lowest $3 \mathrm{~km}$ of all the dropsondes in this study is $5.4 \mathrm{~km}$.

The dropsonde quasi-vertical profiles through DPoI A show relatively constant tangential wind of $20 \mathrm{~m} \mathrm{~s}^{-1}$ with height (Fig. 6a) and outflow of $\sim 5 \mathrm{~m} \mathrm{~s}^{-1}$ (Fig. 6b). The profile also shows that the temperature (Fig. 6c) drops below the mean at $\sim 1.4-\mathrm{km}$ altitude, the average BL height during this period determined by where the inflow was $10 \%$ of its peak value (similar to Zhang et al. 2011). The specific humidity (Fig. 6d) drops below the mean profile at $\sim 1.0-\mathrm{km}$ altitude. The $\theta_{e}$ (Fig. 6e) has a similar signature to the specific humidity and indicates the dropsonde entered the downdraft induced low $\theta_{e}$ air at $\sim 1-1.5-\mathrm{km}$ altitude.
DPoI B represents the lowest 10-m $\theta_{e}$ value observed during P1. It is accompanied by a stronger downdraft $\left(\sim 5 \mathrm{~m} \mathrm{~s}^{-1}\right)$ than DPoI A that maximizes at $\sim 6-\mathrm{km}$ altitude (Fig. 4b). The downdraft is upshear, in the direction of the vortex tilt, and embedded in a broad area of convergence at $\sim 8 \mathrm{~km}$ (not shown) leading to widespread downdrafts throughout the atmosphere (Figs. $5 \mathrm{a}-\mathrm{c}$ ). The reflectivity values at the location of strongest descent are only $10 \mathrm{~dB} Z$ and the values of up to $30 \mathrm{~dB} Z$ below the strongest subsidence indicate a bright band.

The quasi-vertical profiles through DPoI B (Fig. 6) show increasing tangential wind with height to a maximum value of $\sim 30 \mathrm{~m} \mathrm{~s}^{-1}$ and alternating inflow and outflow within the BL. In terms of thermodynamics, there is a temperature inversion of $\sim 1^{\circ} \mathrm{C}$ along with moistening of $4 \mathrm{~g} \mathrm{~kg}^{-1}$ at $\sim 750$-m attitude. The relatively low specific humidity values in the quasi-vertical profile above $1 \mathrm{~km}$ suggest that the dropsonde interacted with the downdraft above the BL. The inversion in the $\mathrm{BL}$ indicates that either the BL is capping the lowest $\theta_{e}$ air from entering or has already started recovering from a flux of low $\theta_{e}$ air (discussed in depth below). 

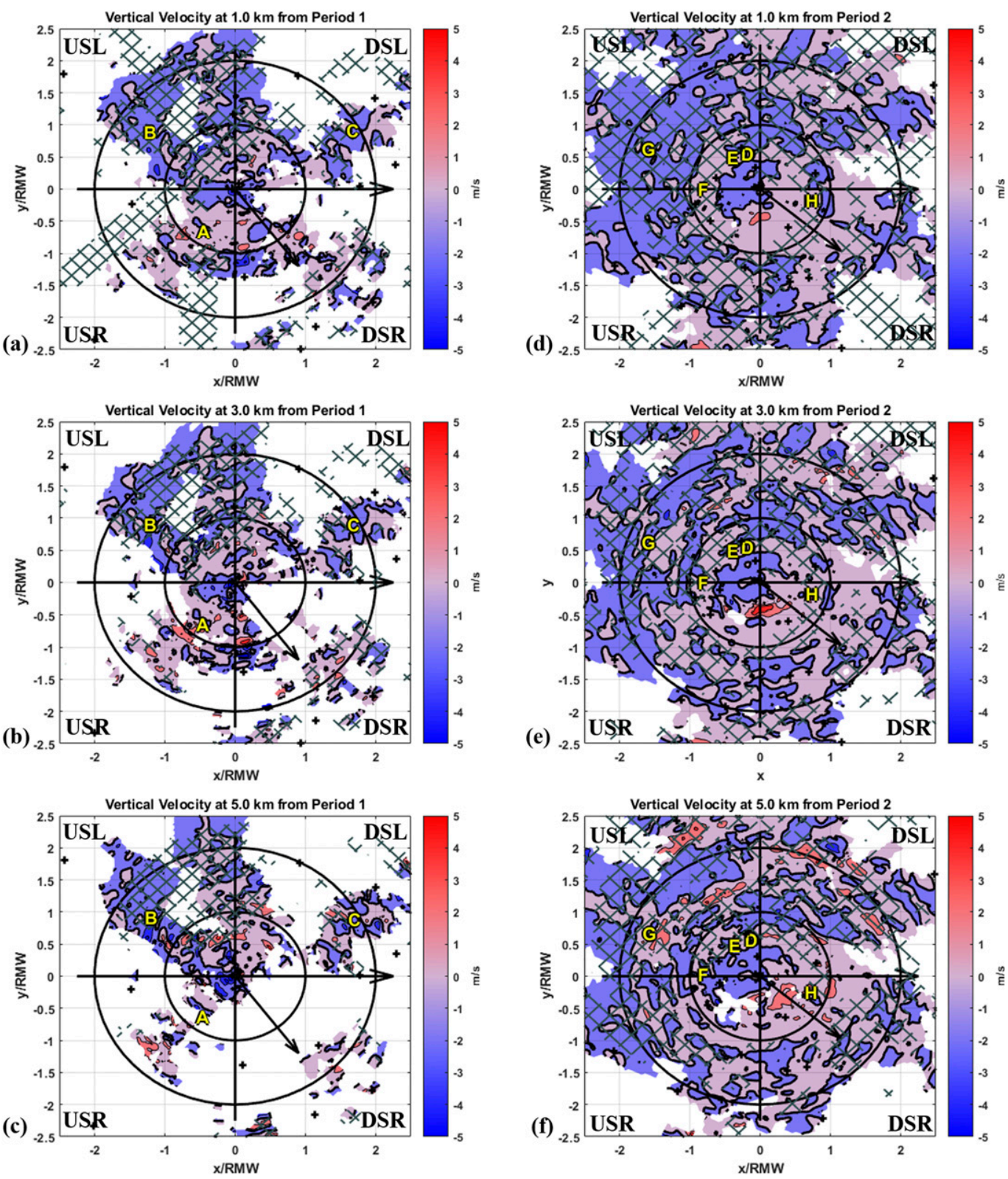

FIG. 5. Normalized radial and shear-rotated (pointing to the right) vertical velocity from the Doppler radar-merged analysis at (a) $1.0 \mathrm{~km}$ during period 1 , (b) $3.0 \mathrm{~km}$ during period 1 , (c) $5.0 \mathrm{~km}$ during period 1 , (d) $1.0 \mathrm{~km}$ during period 2, (e) $3.0 \mathrm{~km}$ during period 2 , and (f) $5.0 \mathrm{~km}$ during period 2 . In all plots the contour interval is $4 \mathrm{~m} \mathrm{~s}^{-1}$. The zero-vertical velocity line is in boldface. Patching is for areas where the reflectivity exceeds $25 \mathrm{~dB} Z$. Storm motion is indicated by the short black arrow, and radial bands of $r^{*}=1$ and $r^{*}=2$ are overlaid. The DPoIs and other dropsonde locations at $10 \mathrm{~m}$ are also overlaid.

DPoI C lies just inside $r^{*}=2$ in the downshear-left (DSL) quadrant. The radar cross section is characterized by a $\sim 1.5 \mathrm{~m} \mathrm{~s}^{-1}$ downdraft maximized at $\sim 6-\mathrm{km}$ altitude (Fig. 4c), with only weak subsidence near the surface. This location has a $10-\mathrm{m}$ temperature and specific humidity of $\sim 27.5^{\circ} \mathrm{C}$ and $19.5 \mathrm{~g} \mathrm{~kg}^{-1}$, respectively. The quasi-vertical profiles through DPoI C (Fig. 6) show a peak tangential wind of $\sim 30 \mathrm{~m} \mathrm{~s}^{-1}$ and radial inflow of $\sim 5 \mathrm{~m} \mathrm{~s}^{-1}$ in the BL. The location is surrounded by weak downdrafts throughout the lower atmosphere (Figs. 5a-c). The specific humidity and temperature are similar to the average sounding from the surface to $\sim 2 \mathrm{~km}$ altitude, but is the driest of the DPoIs above $2 \mathrm{~km}$. The dry air aloft may be advecting into the BL 

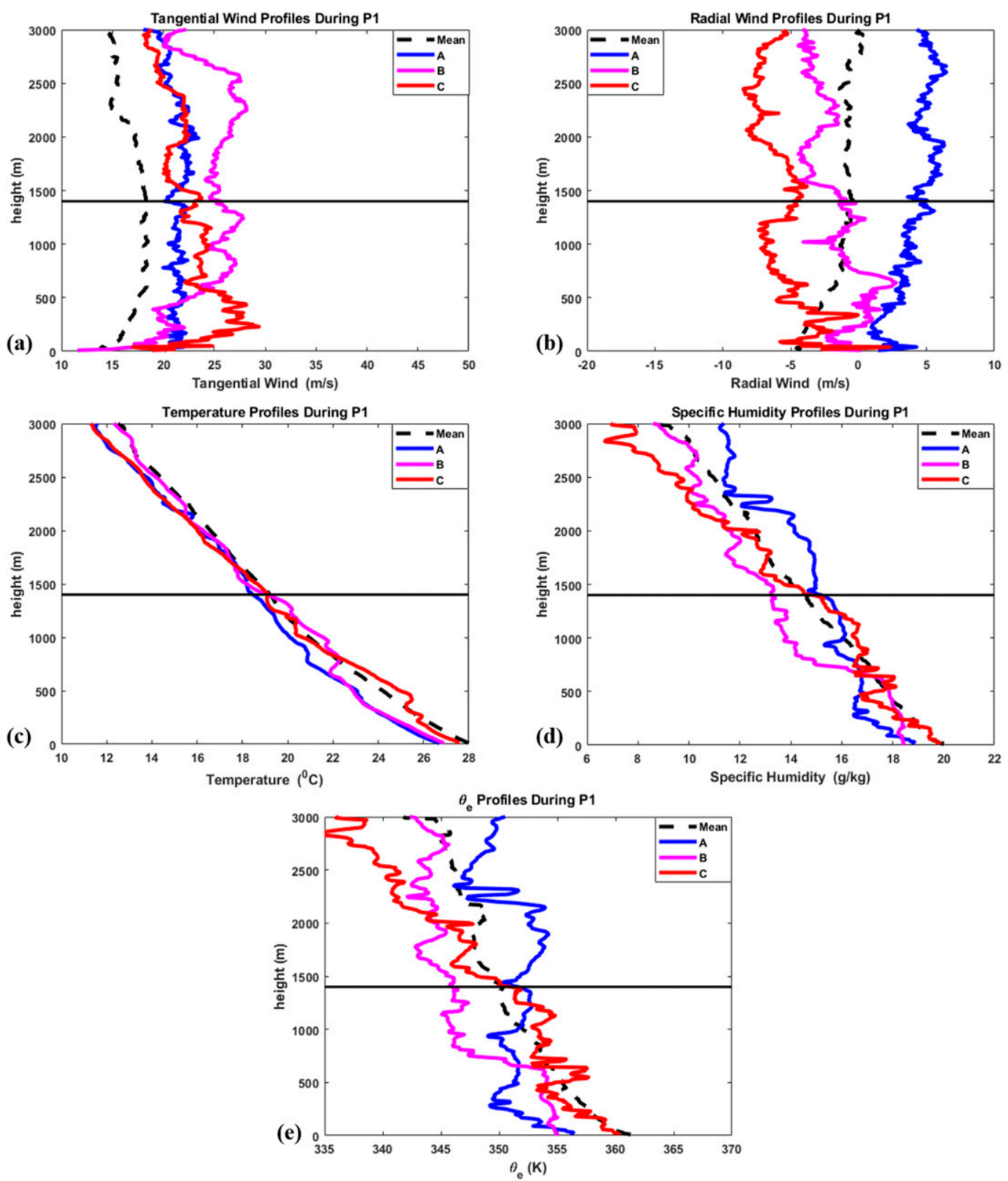

FIG. 6. Quasi-vertical profiles of (a) tangential wind, (b) radial wind, (c) air temperature, (d) specific humidity, and (e) $\theta_{e}$ from dropsondes released during P1. Profiles though DPoIs A-C are plotted along with the mean profiles from the period. The horizontal line is the mean BL height determined from the dropsondes.

downwind though the broad weak downdrafts, causing the low $\theta_{e}$ signature that extends around the storm.

The primary mechanisms for BL recovery examined in this study are air-sea enthalpy fluxes, eye-eyewall mixing, and turbulent mixing. The SST during this time period has a mean of $\sim 29.5^{\circ} \mathrm{C}$, with a cross-storm variability of $0.4^{\circ} \mathrm{C}$ and larger values downshear (Fig. 7a). Combining that with the $10-\mathrm{m}$ thermodynamics, at DPoI A the latent heat flux is $\sim 350 \mathrm{~W} \mathrm{~m}^{-2}$ and the sensible heat flux is $\sim 40 \mathrm{~W} \mathrm{~m}^{-2}$ (Figs. $8 \mathrm{a}, \mathrm{b}$ ). Both of these values are lower than those observed during $\mathrm{P} 2$, primarily because the wind speed at DPoI A is $\sim 15 \mathrm{~m} \mathrm{~s}^{-1}$.

Eye-eyewall mixing can contribute to BL recovery if high $\theta_{e}$ air from the eye is advected into the eyewall through an outflow layer. Recall that DPoI A is in the inner eyewall with a quasi-vertical profile characterized by outflow at all altitudes. Multiple studies have shown that air from the eye can mix into the eyewall and allow 

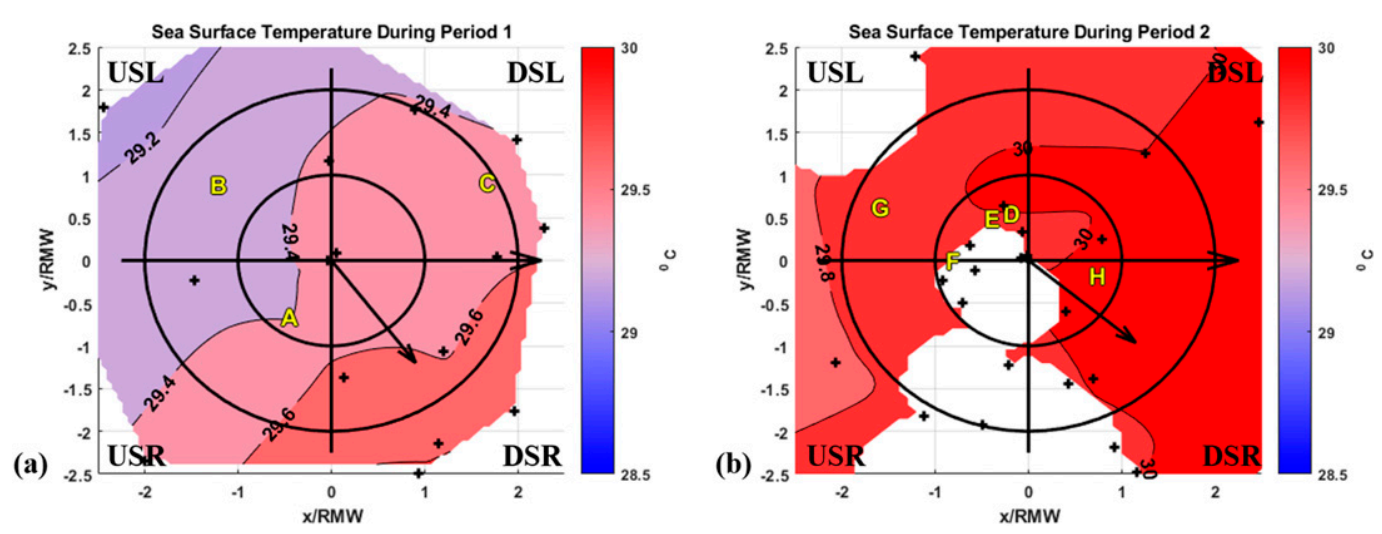

FIG. 7. (a) Normalized radial and shear-rotated (pointing to the right) sea surface temperature during period 1 and (b) sea surface temperature during period 2. DPoIs during each time period are outlined with " +" representing dropsondes not considered DPoIs, storm motion is indicated by the short black arrow, and radial bands of $r^{*}=1$ and $r^{*}=2$ are overlaid. The contouring intervals are $0.2^{\circ} \mathrm{C}$.

the storm to intensify (e.g., Eastin et al. 2005a,b; Cram et al. 2007; Barnes and Fuentes 2010; Dolling and Barnes 2012, 2014).

Atmospheric turbulent eddies that lead to rapid mixing are likely an important factor for the maintenance of high $\theta_{e}$ air advecting into the eyewall. Multiple studies show that turbulent eddies in the hurricane BL influence the air-sea enthalpy fluxes (Etling and Brown 1993; Young et al. 2002; Zhang et al. 2008b). To detect the potential for turbulent mixing, a gradient Richardson number [Rig; Eq. (3); Chandrasekhar (1961); Miles (1961)] is computed at each DPoI:

$$
\text { Rig }=\frac{\text { Buoyancy }}{\text { Shear }}=\frac{\frac{g}{T_{v 0}} \frac{\partial T_{v}}{\partial z}}{\left(\frac{\partial u}{\partial z}\right)^{2}} .
$$

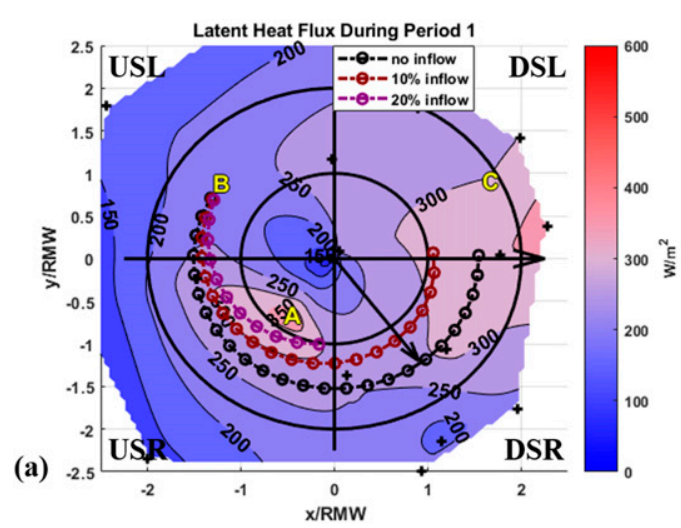

Here, $T_{v}$ is the virtual temperature, $u$ is total wind speed, and $g$ is the acceleration caused by gravity. The $\mathrm{Ri}_{g}$ is calculated for two layers: the lowest part of the $\mathrm{BL}$ $(60-10 \mathrm{~m})$ and a typically more stable region (160$110 \mathrm{~m}$ ). To stabilize the calculation, the profiles of $T_{v}$ and wind speeds were averaged over the top and bottom $20 \mathrm{~m}$ of the layers before taking a derivative. In each layer, the $\mathrm{Ri}_{g}$ is compared to the critical value of 0.25 (though turbulence can sustain until $\mathrm{Ri}_{g}$ approaches $1.0)$, with values below criticality indicating a potential for turbulent mixing. The results are presented in Table 3. During P1, the $\mathrm{Ri}_{g}$ was below criticality for all of the DPoIs in the lower layer, while it was only below criticality at DPoI C in the upper layer. Of note, the negative $\mathrm{Ri}_{g}$ values are indicative of unstable stratification, and the presence of turbulence due to free convection.

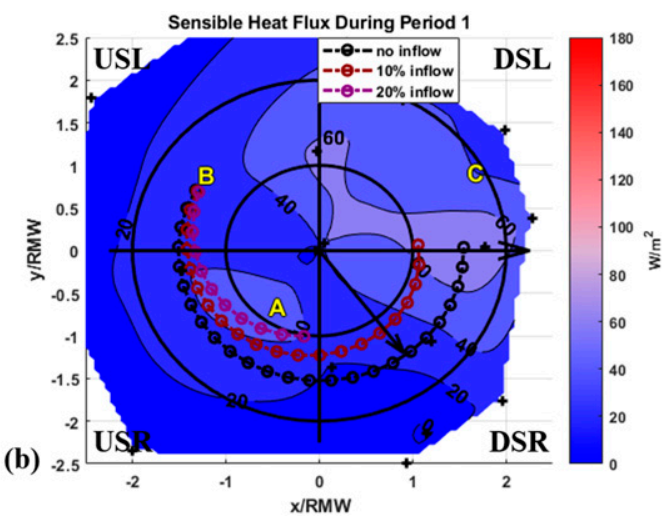

FIG. 8. (a) Normalized radial and shear-rotated (pointing to the right) latent heat flux and (b) sensible heat flux during period 1. DPoIs A, B, and C are outlined with "+" representing dropsondes not considered DPoIs, storm motion is indicated by the short black arrow, and radial bands of $r^{*}=1$ and $r^{*}=2$ are overlaid. The three streamlines examined in the boundary layer recovery calculation are also overlaid. The contouring interval in (a) is $50 \mathrm{~W} \mathrm{~m}^{-2}$ and in (b) it is $20 \mathrm{~W} \mathrm{~m}^{-2}$. 
TABLE 3. List of gradient Richardson numbers at each DPoI. To calculate the derivatives, three grid points were averaged for both the top and bottom layers.

\begin{tabular}{ccc}
\hline $\begin{array}{c}\text { Dropsonde point of } \\
\text { interest (DPoI) }\end{array}$ & $\begin{array}{r}\mathrm{Ri}_{g} \text { in layer from } \\
60 \text { to } 10 \mathrm{~m}\end{array}$ & $\begin{array}{c}\mathrm{Ri}_{g} \text { in layer from } \\
160 \text { to } 110 \mathrm{~m}\end{array}$ \\
\hline $\mathrm{A}$ & -0.071 & 0.276 \\
$\mathrm{~B}$ & -0.002 & 0.339 \\
$\mathrm{C}$ & -0.017 & 0.140 \\
$\mathrm{D}$ & 0.031 & 4.717 \\
$\mathrm{E}$ & -0.035 & 2.329 \\
$\mathrm{~F}$ & -0.004 & 189.1 \\
$\mathrm{G}$ & -0.453 & 0.184 \\
$\mathrm{H}$ & 2.514 & 0.392 \\
\hline
\end{tabular}

While, with these datasets, the total amount of heating and moistening (and the relative roles of each recovery mechanism) for parcels inside the RMW cannot be estimated because of the quick eddy turnover time scale, parcels outside the RMW have a longer time to recover. The calculation for integrated BL recovery for varying inflow angles is presented in the appendix and determines whether the enthalpy fluxes alone are sufficient to recover the BL. For DPoI B, the heating and moistening associated with the air-sea fluxes in a purely tangential trajectory to the end of the DSR quadrant, the best-case scenario for BL recovery, is $12.7 \mathrm{~K}$. When the inflow strength is $10 \%(20 \%)$ of the tangential wind, the heating and moistening is $10.9(6.2) \mathrm{K}$. With an inflow strength of $20 \%$ of the mean tangential wind, the parcels reach the RMW before the end of the DSR quadrant. In each scenario, the integrated air-sea heat fluxes are enough to recover the low $\theta_{e}$ air. The large magnitudes of the recovery can be attributed to the shallow BL depth $(640 \mathrm{~m})$ and weak tangential wind speeds that lead to a long integration time. The enhanced heating and moistening may also explain the onset of RI, or indicate that other processes are limiting the $\mathrm{BL}$ recovery. No BL recovery calculation was made for DPoI C since it is at a radial distance of $r^{*} \sim 2$ and the integration time would be unrealistically long.

\section{b. Period 2: During RI}

The 10-m air temperature inside the RMW is $\sim 0.5^{\circ} \mathrm{C}$ cooler than in P1 (Fig. 9a). There is a larger radial temperature gradient in the downshear quadrants with all of the minima located inside the RMW. The USR quadrant has the warmest $10-\mathrm{m}$ air temperature and lowest specific humidity outside the RMW (Fig. 9b) which may indicate the presence of either weak and broad subsidence or entrainment of environmental air.
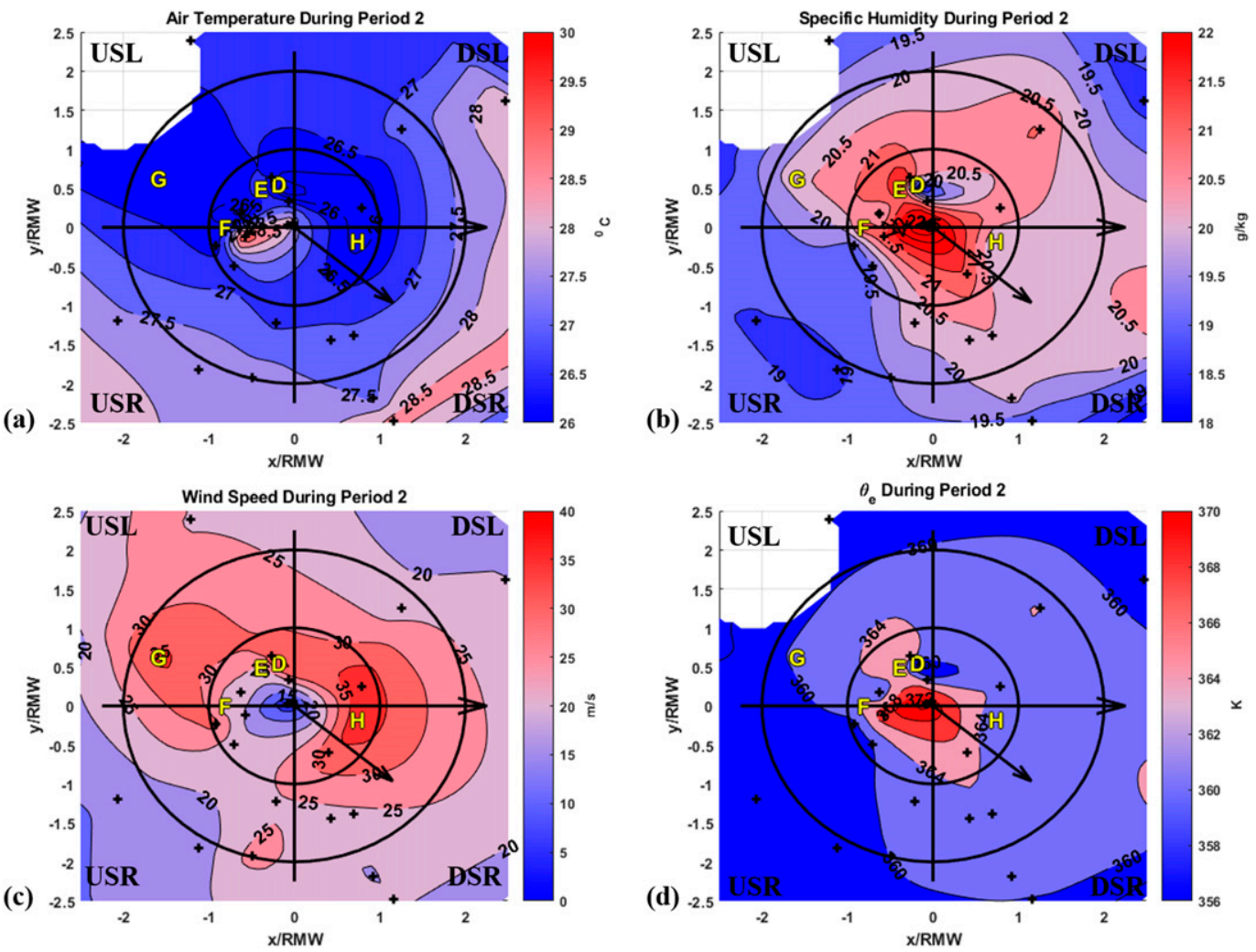

FIG. 9. As in Fig. 3, but for DPoIs D-H in period 2. 

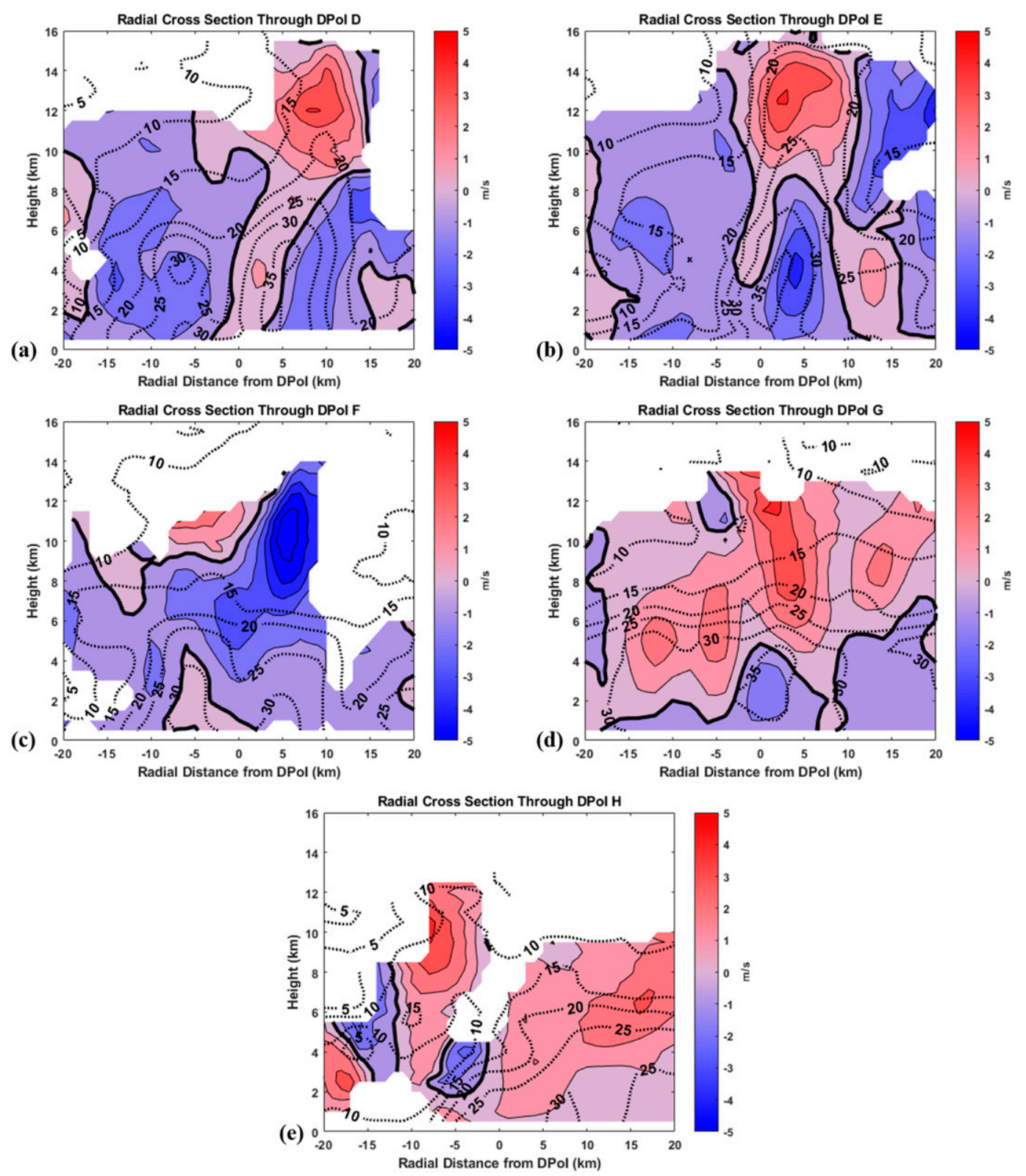

FIG. 10. Radial cross sections of Doppler radar-derived vertical velocities at splash locations of (a) DPoI D, (b) DPoI E, (c) DPoI F, (d) DPoI G, and (e) DPoI H. The shading is vertical velocity at contouring intervals of $1.0 \mathrm{~m} \mathrm{~s}^{-1}$. The zero-vertical velocity line is in boldface. Reflectivity is contoured at 5-dBZ intervals with dashed contours.

The $\theta_{e}$ pattern (Fig. 9d) largely mimics that seen in the specific humidity field, with the most interesting characteristic being the high and low $\theta_{e}$ couplet in the USL quadrant (DPoIs $\mathrm{E}$ and $\mathrm{D}$, respectively). The peak storm-relative wind speed is $\sim 15 \mathrm{~m} \mathrm{~s}^{-1}$ stronger during P2 (Fig. 9c). The maximum wind speeds of $\sim 35 \mathrm{~m} \mathrm{~s}^{-1}$ occur downshear. The general asymmetric structure of the wind speed between the upshear and downshear quadrants is similar to that from both weak and mature
TCs in a composite scatterometer database (Klotz and Jiang 2017).

DPoI D, the point with the lowest observed $\theta_{e}$ during $\mathrm{P} 2$, has an updraft that extends from $\sim 1$ - to $\sim 7.5-\mathrm{km}$ altitude and tilts radially outward (Fig. 10a). In the cross section, broad areas of sinking motion surround the updraft. This is reiterated in the storm-scale view (Figs. 5d-f), though multiple swaths sample the inner core during this period, smoothing convective 

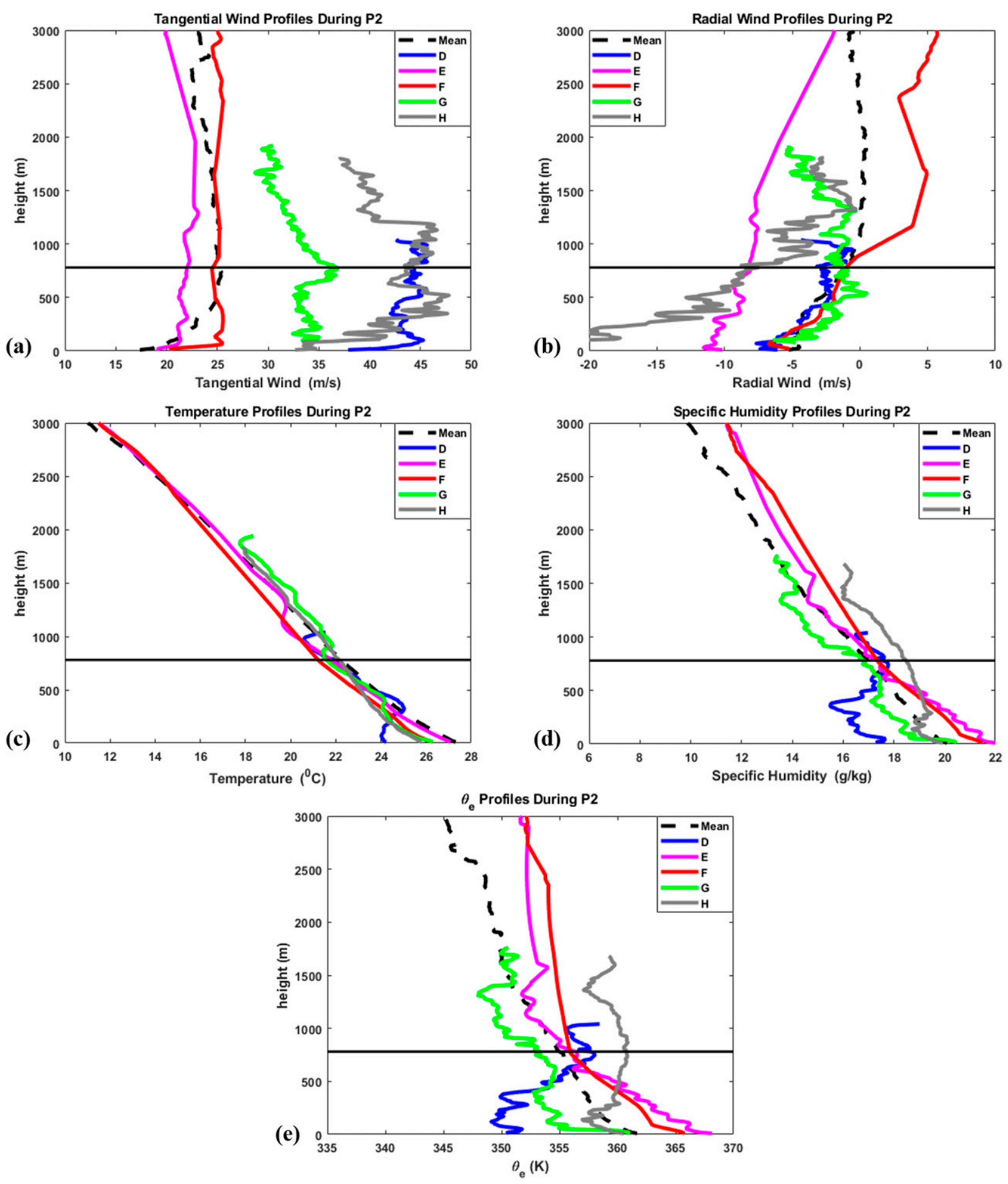

FIG. 11. As in Fig. 6, but for DPoIs D-H in period 2.

characteristics. The nearly zero vertical velocity in the reflectivity maximum of the cross section indicates that little evaporation has occurred, even though the reflectivity is greater than $35 \mathrm{dBZ}$. The quasi-vertical profiles through DPoI D (Fig. 11) show that the tangential wind peaks at $\sim 45 \mathrm{~m} \mathrm{~s}^{-1}$ in the lower BL. The radial wind peaks at $\sim 5 \mathrm{~m} \mathrm{~s}^{-1}$ of inflow near the surface and decreases to near zero at the top of the BL. The 
temperature and specific humidity profiles at DPoI D have the greatest decrease in the $\mathrm{BL}(\sim 750 \mathrm{~m})$ during either period.

Downwind is DPoI E, representing the largest observed $\theta_{e}$ during $\mathrm{P} 2$. This cross section contains a strong downdraft that is able to penetrate into the BL (Fig. 10b), in a similar reflectivity profile as DPoI D. The quasi-vertical profiles through DPoI E (Fig. 11) shows tangential winds of $\sim 20 \mathrm{~m} \mathrm{~s}^{-1}$, much weaker than that at DPoI D. The inflow was $10 \mathrm{~m} \mathrm{~s}^{-1}$ at the surface and decreased with height to $\sim 5 \mathrm{~m} \mathrm{~s}^{-1}$ at $3 \mathrm{~km}$. The thermodynamic profiles through DPoI E provide evidence of warming and moistening in the lowest kilometer. The moistening is consistent with enhanced evaporation rates and the warming is likely an adiabatic offset to the evaporation. The comparison between DPoIs D and $\mathrm{E}$ indicate that the magnitude of the vertical velocity is related to the near-surface temperature, specific humidity, and $\theta_{e}$. The similar amount of hydrometeors in the cross sections indicates that the low-level reflectivity signature is unable to capture the amount of evaporation and cooling taking place.

Since the dropsonde in DPoI E was released from the high-altitude DC-8 aircraft that was flying simultaneously with the P-3, a complete skew $T-\log p$ graph is given in Fig. 12. A downdraft is evident in a relatively warm and dry layer that extends from $\sim 920$ to $\sim 620 \mathrm{hPa}(650-4000 \mathrm{~m})$. The inversion layer extends above the altitudes shown in Fig. 11, and its extent is not captured in the $3-\mathrm{km}$ profiles. Thus, any determination of the source of air parcels from shallow dropsonde profiles released by the P-3 should be interpreted with caution.

Downwind of the two points discussed above is DPoI F, located just inside the RMW, between the USL and USR quadrants. This location has a $10-\mathrm{m}$ air temperature $\left(\sim 26.5^{\circ} \mathrm{C}\right)$ and specific humidity $\left(\sim 20.5 \mathrm{~g} \mathrm{~kg}^{-1}\right)$ comparable to those of DPoI E. The cross section is characterized by the largest downdraft magnitude in this study that is maximized near $12-\mathrm{km}$ altitude (Fig. 10c). The downdraft reaches the BL, but at a much weaker magnitude than aloft. The large-scale view shows that DPoI F is downwind of an elongated area of weak updrafts at the RMW (cf. Figs. 5d-f). The quasivertical profile through DPoI F shows $\sim 25 \mathrm{~m} \mathrm{~s}^{-1}$ tangential wind throughout the BL. The inflow in the BL is $\sim 5 \mathrm{~m} \mathrm{~s}^{-1}$, which becomes $\sim 5 \mathrm{~m} \mathrm{~s}^{-1}$ outflow above the $\mathrm{BL}$. There is also cooling and drying relative to the mean sounding at DPoI F, signifying that this dropsonde likely never interacted with the air produced by the strongest vertical velocities aloft.

At a farther radius, DPoI $\mathrm{G}$ has a lower $10-\mathrm{m}$ air temperature $\left(\sim 26^{\circ} \mathrm{C}\right)$, but higher specific humidity

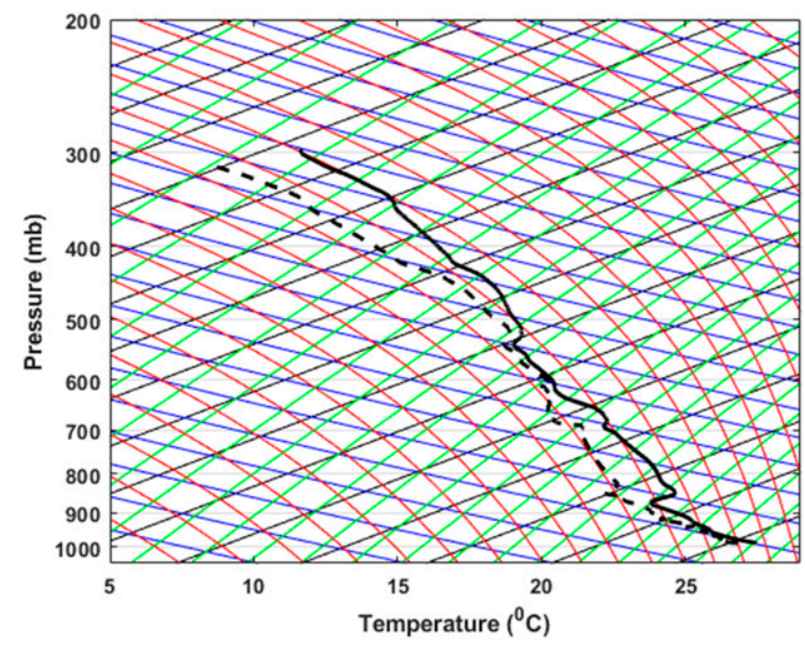

FIG. 12. Skew $T-\log p$ diagram depicting temperature (solid line) and dewpoint (dashed line) profiles through DPoI E.

$\left(\sim 20 \mathrm{~g} \mathrm{~kg}^{-1}\right)$ than the average value at that radius. In the low levels of the radar cross section (Fig. 10d), there is a downdraft of order $\sim 1 \mathrm{~m} \mathrm{~s}^{-1}$ that reaches the surface. The downdraft is underneath a region of convective updrafts. The shallowness of the downdraft is the most likely reason the $10-\mathrm{m}$ specific humidity is not larger, though the air could originate from the broad downdrafts observed upstream (Figs. 5d-f). As with DPoI E, the maximum of the downdraft at DPoI G is collocated with a reflectivity maximum. The quasi-vertical profiles through DPoI $G$ indicate cooling and drying in the lowest $500 \mathrm{~m}$, though both increase sharply right above the surface. The tangential wind profile shows a relatively constant value of $35 \mathrm{~m} \mathrm{~s}^{-1}$ in the BL. The radial wind is $\sim 5 \mathrm{~m} \mathrm{~s}^{-1}$ of inflow near the surface decreasing to nearly zero at the top of the BL.

DPoI $\mathrm{H}$ is inside the RMW of the DSR quadrant, the most favorable location for convective initiation (e.g., DeHart et al. 2014; Wadler et al. 2018). Both the temperature and specific humidity are average values for this radius $\left(\sim 26^{\circ} \mathrm{C}\right.$ and $20.5 \mathrm{~g} \mathrm{~kg}^{-1}$, respectively) which leads to a $10-\mathrm{m} \theta_{e}$ of $\sim 364 \mathrm{~K}$. The radar cross section (Fig. 10e) shows an area of low-level updrafts. The broadness of the updrafts is reaffirmed in the stormscale view (Figs. 5d-f). The reflectivity contours are tilted upward in the region, an indicator that hydrometeors are being advected upward. The peak inflow exceeds $20 \mathrm{~m} \mathrm{~s}^{-1}$ and the tangential wind peaks at $\sim 48 \mathrm{~m} \mathrm{~s}^{-1}$ through the quasi-vertical profile at DPoI $\mathrm{H}$ (Fig. 11). The $\theta_{e}$ at DPoI $\mathrm{H}$ is higher than the mean sounding at altitudes above $500 \mathrm{~m}$, indicating favorability for the development of convection. However, there is a sharp decrease in $\theta_{e}$ starting at 500-m altitude, mostly determined by a drop in specific humidity. 

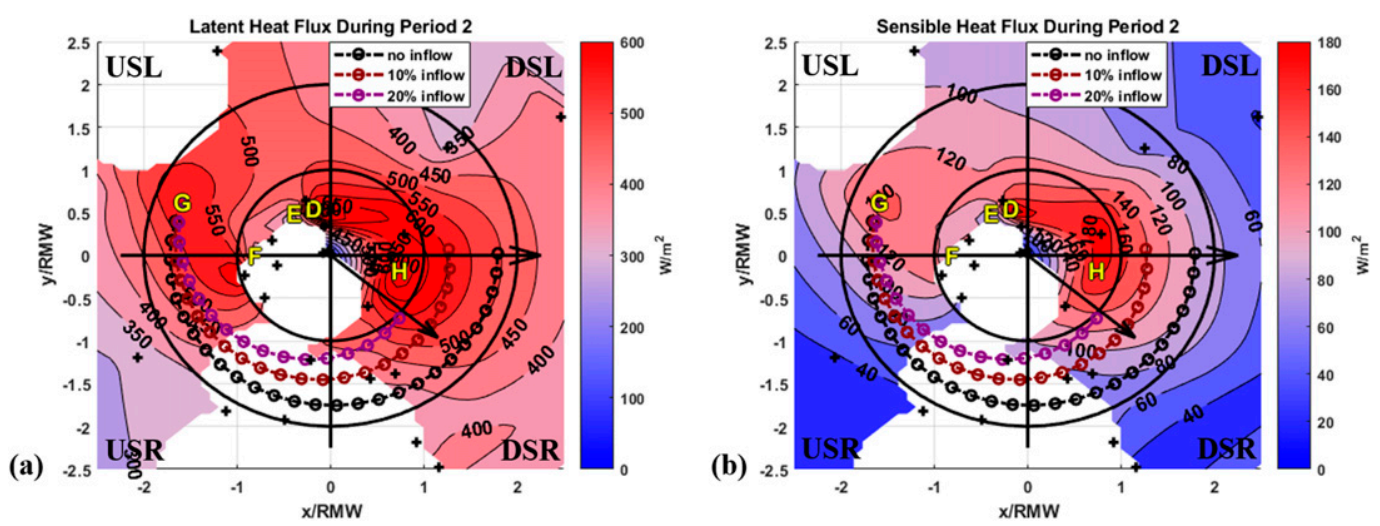

FIG. 13. As in Fig. 8, but for DPoIs D-H in period 2.

As in P1, the SST was largely uniform over the domain (Fig. 7b). It is approximately $0.5^{\circ} \mathrm{C}$ warmer during P2, with the larger values downshear and in the direction of storm motion. As Earl was continuously intensifying during P2, one would expect generally higher enthalpy fluxes and for any low entropy air entering the BL near the eyewall to quickly recover.

The cooler and drier downdraft in DPoI D is associated with a latent heat flux of $\sim 650 \mathrm{~W} \mathrm{~m}^{-2}$ and a sensible heat flux of $\sim 180 \mathrm{~W} \mathrm{~m}^{-2}$ (Figs. 13a and 13b, respectively). DPoI E is associated with a latent heat flux of $400 \mathrm{~W} \mathrm{~m}^{-2}$ and a sensible heat flux of $\sim 80 \mathrm{~W} \mathrm{~m}^{-2}$. The hypothesized enhanced evaporation at DPoI E significantly reduced the amount of heat fluxes necessary for $\mathrm{BL}$ recovery. Since the $\mathrm{Ri}_{g}$ is below criticality at both locations (Table 3), it is likely that their recovery is aided by turbulent mixing. Additionally, given their radial location, eye-eyewall mixing is likely also aiding recovery. A similar logic for BL recovery applies for DPoI F

The integrated BL recovery calculation for DPoI G (the appendix) determines whether parcels associated with this downdraft can recover solely through the airsea enthalpy fluxes for three different radial inflow strengths. The best-case calculation of a truly azimuthal streamline yielded a BL recovery of $6.2 \mathrm{~K}$, an ample amount of heating and moistening that is larger than the $\theta_{e}$ difference between air surrounding DPoI G and that in the DSR quadrant. For inflow that was $20 \%$ of the mean tangential wind, the streamline reaches the RMW after a total heating and moistening of $3.8 \mathrm{~K}$. In all situations, the heating and moistening associated with airsea enthalpy fluxes supplies enough energy to increase the $\mathrm{BL} \theta_{e}$ to at least the value at the RMW and convective initiation regions.

DPoI $\mathrm{H}$ required a different thermodynamic evolution, since the vertical velocities near the surface hint at updraft initiation. Potentially, the air-sea enthalpy fluxes created local positive buoyancy that initiates positive vertical velocities. This is consistent with a collocated upward tilt of the reflectivity contours in the updraft region, and provides an additional explanation for how the air-sea heat fluxes impact the storm intensity. Jaimes et al. (2015) discussed implications of enhanced low-level buoyancy during the same time period and showed that localized low-level buoyancy was dominated by the air-sea humidity contrast.

\section{Discussion}

Both before and during Hurricane Earl's RI, cold/dry downdrafts represent potentially negative influences to its intensification rate. Many of the mesoscale downdrafts identified in this study were similar to those hypothesized by Riemer et al. (2010). However, how each downdraft influenced BL thermodynamics varied based on its structure, strength, and storm-relative location. Other properties of the convection (e.g., tilt of convective cores) could also be important to the location and strength of the $\theta_{e}$ anomalies, but is beyond the scope of this manuscript. DPoI A in P1 and DPoIs D, E, and F in P2 were points located on the inner eyewall whose radar cross sections contained downdrafts. These locations all had near-surface reflectivity values exceeding $20 \mathrm{~dB} Z$, with DPoIs D, E, and F having values above $30 \mathrm{~dB} Z$.

The radar cross sections through DPoIs E and F show downdrafts exceeding $2 \mathrm{~m} \mathrm{~s}^{-1}$, though the one in DPoI E is closer to the surface. The quasi-vertical profiles show that these two points have the highest specific humidity values in P2, likely due to evaporation. It is worth noting that an increase of $\theta_{e}$ in air parcels assumes that the evaporated liquid water content was part of the background air and not initially in the parcels. The temperature profiles at these locations are near average, 


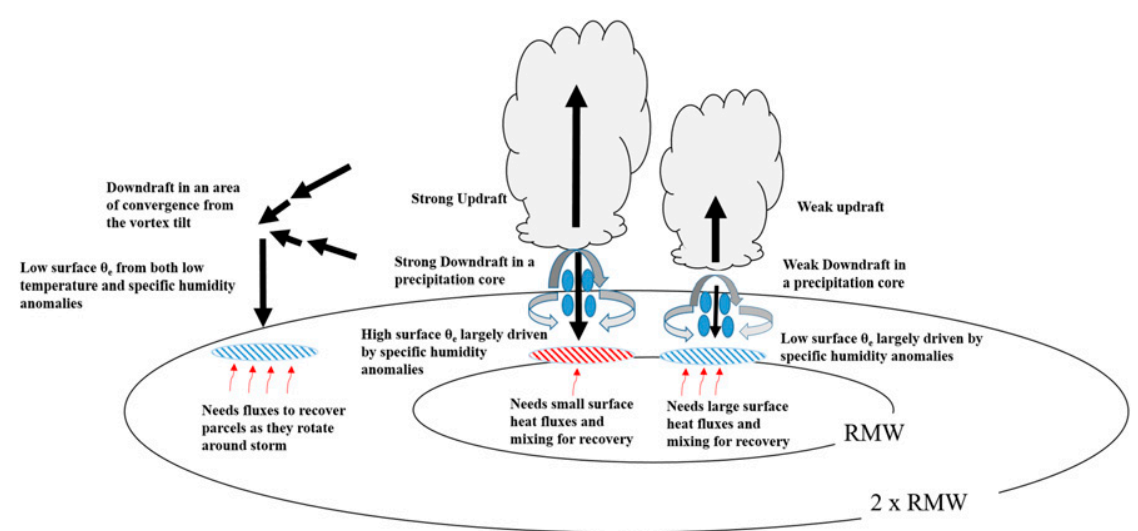

FIG. 14. A summary schematic of the different types of downdrafts identified in this study along with a description of the recovery that is associated with them.

potentially because the cooling caused by evaporation is offset by adiabatic compression. Altogether, the $10-\mathrm{m} \theta_{e}$ at these locations is maximized, showing that air from these strong and moist downdrafts does not significantly impact inner-core BL thermodynamics.

By contrast, weaker $\left(<2 \mathrm{~m} \mathrm{~s}^{-1}\right)$ near-surface downdrafts in DPoIs $\mathrm{A}$ and $\mathrm{D}$ are associated with low $\theta_{e}$ values. The presence of substantial hydrometeors and weak vertical motions indicate less evaporation took place at these DPoIs than those discussed above. Both of these quasi-vertical profiles contain the lowest specific humidities of their respective periods, and have air temperatures lower than the mean profiles. This signature is consistent with cool air outflow from updrafts that cannot adiabatically warm because of weak downward vertical velocities. Even though these weak and dry downdrafts do not deposit substantial amounts of air into the $\mathrm{BL}$, they have the most negative impacts on inner-core BL thermodynamics. A schematic of the differences among the downdrafts identified in this study is presented in Fig. 14.

The varying degree of evaporation and water vapor saturation in downdrafts has been observed (e.g., Zipser 1977; Brown 1979; Knupp and Cotton 1985; Cione et al. 2000). Hookings (1965) showed that in steady-state idealized conditions, faster downdraft speeds are associated with initially lower relative humidity values and that downdrafts gain relative humidity through evaporation of the precipitation core. In a composite framework, Eastin et al. (2005a,b) found that moist downdrafts are often transient, since positive buoyancy from adiabatic warming can overcome negative buoyancy from evaporation. Unsaturated (dry) downdrafts were weakly positively buoyant and usually existed upshear. Thus, the age of the downdraft may be related to its moisture content. Further work on how the magnitude, size, and location of downdrafts varies its effects on TC intensity is ongoing in an idealized modeling framework.

Because of the turbulent nature of the hurricane inner core, low $\theta_{e}$ air associated with downdrafts inside the RMW must recover through a combination of air-sea enthalpy fluxes, turbulent mixing, eye-eyewall mixing, and heat fluxes from above the $\mathrm{BL}$. The $\mathrm{Ri}_{g}$ was below criticality at all the DPoIs except $\mathrm{H}$, providing evidence for the presence of turbulent atmospheric eddies. Turbulent eddies allow for a uniform distribution of $\theta_{e}$, though mixing leads to a cooler and more stable BL; the enthalpy fluxes continuously warm and moisten the region. Eye-eyewall mixing can also recover the BL because of the reservoir of high $\theta_{e}$ that exists in the eye. The separation of time scales and relative importance between the recovery mechanisms is a topic of future work.

DPoIs B and G represent locations outside the RMW that have downdrafts with low $\theta_{e}$ air near the surface. The implications of these downdrafts are different from those identified inside the RMW because they do not immediately influence the eyewall. DPoI B is part of a larger-scale downdraft that is likely caused by the vortex tilt during P1. Though the near-surface reflectivity exceeds $25 \mathrm{dBZ}$, it is not associated with a strong updraft or convective precipitation core. DPoI G contains a lowlevel downdraft below an updraft and precipitation core. The BL recovery calculation in the appendix shows that the heating and moistening of air parcels caused by the air-sea enthalpy fluxes along a purely tangential path from the DPoI to the end of the DSR quadrant are 12.7 and $6.2 \mathrm{~K}$ at DPoIs B and G, respectively. This is substantial enough to recover the $\operatorname{BL} \theta_{e}$ before reaching the end of the DSR quadrant, meaning these points will not inhibit the future development of convection. In a more 
realistic streamline in which the radial wind magnitude was $20 \%$ of the mean tangential wind magnitude, the increase in $\theta_{e}$ caused by the enthalpy fluxes before parcels reach the RMW is 6.2 and $3.8 \mathrm{~K}$ for DPoIs B and G, respectively. Again, the enthalpy fluxes alone provide enough energy for parcels to recover to the $\theta_{e}$ values at the RMW, meaning the $\theta_{e}$ anomalies from these downdrafts will not affect the efficiency of the storm-scale circulation.

For many of the DPoIs in this study, the quasi-vertical profiles show evidence that BL recovery has already begun. In those profiles, the temperature and specific humidity increase in the lowest $\sim 50 \mathrm{~m}$, potentially caused by the oceanic heat fluxes. As shown in Dolling and Barnes (2012), the midlevel temperature inversion caused by downdrafts acts to stabilize the BL through convective inhibition. The inversion stops the upward propagation of $\theta_{e}$ and allows it to build via surface fluxes. Once enough energy builds in the BL, new convection can initiate. This may explain, in part, the periodicity in intense inner-core convection described in Riemer et al. (2010) and Molinari et al. (2013).

\section{Conclusions}

Using a combination of NOAA and NASA dropsondes, P-3 tail Doppler radar, and buoy- and drifter-based SST data, the BL thermodynamic evolution in TC Earl was analyzed for periods before RI and during RI. Properties of 10-m air temperature, specific humidity, and $\theta_{e}$ were related to the convective life cycle and air-sea enthalpy fluxes in a deep layer vertical shear and normalized radial framework.

During both periods, the strength and location of downdrafts were related to the amount of specific humidity, temperature, and $\theta_{e}$ that parcels contain when they are in the BL. Strong downdrafts $\left(>2 \mathrm{~m} \mathrm{~s}^{-1}\right)$ associated with the tilt of the vortex and relatively weak downdrafts associated with convection have the coolest and driest air in the BL and can be the greatest hindrances for TC intensification. Strong downdrafts underneath deep convection can evaporate enough liquid water for the parcels to approach water vapor saturation and contain the highest $\operatorname{BL} \theta_{e}$ seen outside of the eye. The differing amounts of water vapor in parcels have implications on the amount of recovery that is needed before parcels enter the eyewall or convective initiation region.

In all cases, the BL eventually recovered through a combination of air-sea enthalpy fluxes, atmospheric turbulent eddies, eye-eyewall mixing, and heat fluxes from above the BL. The results emphasize the role of air-sea interaction in relation to the life cycle of convection in TCs and document the need to further explore BL recovery relationships over differing oceanic regimes and in TCs that do not intensify. The complex nature of these results also highlights the need for dense inner-core dropsonde and SST observations to fully capture the dynamic and thermodynamic evolution of a TC.

Acknowledgments. We thank all those from the NOAA Aircraft Operations Center for the collection of this dataset and John Gamache for the development of the airborne Doppler radar quality control software. The quality-controlled Doppler radar-merged analyses were gratefully contributed by Dr. Paul Reasor. The comments and suggestions from Drs. Robert Rogers, Jonathan Zawislak, and three anonymous reviewers helped to greatly improve the quality of this manuscript. Joshua Wadler is supported by the National Science Foundation Graduate Research Fellowship under Grant DGE-1451511. Jun Zhang is supported by NOAA Grants NA14NWS4680028 and NA14NWS4680030; NSF Grants AGS1822128, AGS1654831, and AGS1249732; and NASA Grant NNX14AM69G. Lynn K. Shay and Benjamin Jaimes are supported by NASA Grant NNX15AG43G and through a NOAA NESDIS grant.

\section{APPENDIX}

\section{Boundary Layer Recovery Calculation}

The potential of BL recovery for DPoIs B and G through air-sea enthalpy fluxes is examined using a calculation similar to Zhang et al. (2013) and Zhang et al. (2017). Changes in 10-m potential temperature $\theta$ and specific humidity $q$ at a given height caused by surface sensible $\left(Q_{\mathrm{s} 0}\right)$ and latent heat $\left(Q_{l 0}\right)$ fluxes are given by

$$
\begin{aligned}
& \frac{d \theta}{d t}=\frac{\theta}{c_{p} T}\left(-\frac{1}{\rho} \frac{\partial Q_{s}}{\partial z}\right)=\frac{\theta}{c_{p} T}\left(\frac{Q_{s 0}}{\rho \Delta z}\right), \\
& \frac{d q}{d t}=\left(-\frac{1}{\rho} \frac{\partial Q_{l}}{\partial z}\right)=\frac{Q_{l 0}}{\rho L_{v} \Delta z},
\end{aligned}
$$

where $\Delta z$ is the BL height. Note that this calculation ignores the potential for sensible heat flux above the BL (i.e., other cold/dry downdrafts interacting with the air parcel), which was identified to be just as significant as the enthalpy fluxes in Anthes and Chang (1978) and Kepert et al. (2016). The BL height is defined where the average vertical profile of radial wind was $10 \%$ of its peak value, a calculation similar to Zhang et al. (2011). The average vertical profile of radial wind is determined 
TABLE A1. A summary of the averaged values along the parcel trajectory used in Eqs. (A1)-(A4) for the boundary layer recovery of DPoI B.

\begin{tabular}{|c|c|c|c|c|c|c|c|c|c|c|c|}
\hline $\begin{array}{l}\text { Inflow } \\
\text { percent } \\
\text { (percent of } \\
\text { tangential } \\
\text { wind) }\end{array}$ & $\begin{array}{l}\text { Latent } \\
\text { heat flux } \\
\left(\mathrm{W} \mathrm{m}^{-2}\right)\end{array}$ & $\begin{array}{l}\text { Sensible } \\
\text { heat flux } \\
\left(\mathrm{W} \mathrm{m}^{-2}\right)\end{array}$ & $\begin{array}{c}\text { Temperature } \\
\text { (K) }\end{array}$ & $\begin{array}{c}\text { Potential } \\
\text { temperature } \\
(\mathrm{K})\end{array}$ & $\begin{array}{c}\text { Density } \\
\left(\mathrm{kg} \mathrm{m}^{-3}\right)\end{array}$ & $\begin{array}{c}D \theta / d t \\
\left(\mathrm{~K} \mathrm{~h}^{-1}\right)\end{array}$ & $\begin{array}{c}D q / d t \\
\left(\mathrm{~g} \mathrm{~kg}^{-1} \mathrm{~h}^{-1}\right)\end{array}$ & $\begin{array}{c}T_{\mathrm{LCL}} \\
(\mathrm{K})\end{array}$ & $\begin{array}{c}\theta_{e} \\
(\mathrm{~K})\end{array}$ & $\begin{array}{c}D \theta_{e} / d t \\
\left(\mathrm{~K} \mathrm{~h}^{-1}\right)\end{array}$ & $\begin{array}{c}\text { Total } \theta_{e} \\
\text { change } \\
\text { along } \\
\text { streamline } \\
\quad(\mathrm{K})\end{array}$ \\
\hline No inflow & 278.0 & 35.6 & 300.8 & 300.7 & 1.15 & 0.17 & 0.54 & 297.0 & 359.4 & 1.85 & 12.7 \\
\hline $10 \%$ & 282.2 & 38.1 & 300.7 & 300.6 & 1.15 & 0.19 & 0.55 & 297.0 & 359.3 & 1.89 & 11.0 \\
\hline $20 \%$ & 288.8 & 39.8 & 300.4 & 300.3 & 1.15 & 0.19 & 0.56 & 296.7 & 357.7 & 1.93 & 6.2 \\
\hline
\end{tabular}

by averaging the DPoI and every dropsonde profile outside of the RMW, downwind to the end of the DSR quadrant. Dropsondes inside the RMW were not included because the inflow layer converges in this region. Seven dropsondes were averaged for DPoI B and eight were averaged for DPoI G. The BL height was $640 \mathrm{~m}$ for DPoI B and $1310 \mathrm{~m}$ for DPoI G. Changes to the height of the inflow layer can also change the extent that $\theta_{e}$ anomalies are able to reach the eyewall (e.g., Barnes and Powell 1995; Barnes and Dolling 2013).

All other variables in the equations were found by averaging along a streamline in the $10-\mathrm{m}$ contour plots. For both DPoIs examined, three streamlines representing varying amounts of inflow, are analyzed. Attempts to create a more accurate streamline by using the dropsonde and Doppler radar-derived radial wind were done, but lack of spatial coverage of wind speeds in both the radar and dropsondes increased the uncertainty. The best-case scenario for BL recovery is the purely tangential streamline that extends from the DPoI to the end of the DSR quadrant, while the more realistic estimate is the streamline with a radial inflow magnitude that is $20 \%$ of the mean tangential wind magnitude. With the enhanced inflow, the streamlines reach the RMW before the end of the DSR quadrant. The average tangential wind magnitude was obtained from the $10-\mathrm{m}$ value, though the integration time and total heating and moistening would be reduced at higher altitudes where the winds speeds are larger (Kepert 2006a,b).
The streamlines account for all conditions a parcel would experience as it traverses around the storm, but is limited by the assumptions of steady-state conditions, spare data sampling, and the heat fluxes decreasing linearly with height from the sea surface to top of the BL. To estimate the $\theta_{e}$ changes caused by the enthalpy fluxes, we apply logarithmic differentiation to the $\theta_{e}$ equation shown below:

$$
\theta_{e}=\theta \exp \left(\frac{L_{v} q}{c_{p} T_{\mathrm{LCL}}}\right),
$$

to obtain the equation for the rate of change in $\theta_{e}$. After differentiation the equation obtains the following form:

$$
\frac{d \theta_{e}}{d t}=\frac{\theta_{e}}{\theta} \frac{d \theta}{d t}+\frac{\theta_{e} L_{v}}{c_{p} T_{\mathrm{LCL}}} \frac{d q}{d t},
$$

where $T_{\mathrm{LCL}}$ is the temperature at the lifting condensation level, calculated following Bolton (1980); $T_{\mathrm{LCL}}$ and $\theta_{e}$ were averaged along the same azimuthal streamlines described above. Values obtained for Eqs. (A1)-(A4) are presented in Tables A1 and A2 for DPoIs B and G, respectively. While variations caused by expected errors in the interpolation scheme should not significantly modify the results, the changes in $\theta_{e}$ are sensitive to the BL height. Implications of this calculation are discussed in the main text.

TABLE A2. A summary of the averaged values along the parcel trajectory used in Eqs. (A1)-(A4) for the boundary layer recovery of DPoI G.

\begin{tabular}{lccccccccccc}
\hline \hline & $\begin{array}{c}\text { Latent } \\
\text { heat flux } \\
\left(\mathrm{W} \mathrm{m}^{-2}\right)\end{array}$ & $\begin{array}{c}\text { Sensible } \\
\text { heat flux } \\
\left(\mathrm{W} \mathrm{m}^{-2}\right)\end{array}$ & $\begin{array}{c}\text { Temperature } \\
(\mathrm{K})\end{array}$ & $\begin{array}{c}\text { Potential } \\
\text { temperature } \\
(\mathrm{K})\end{array}$ & $\begin{array}{c}\text { Density } \\
\left(\mathrm{kg} \mathrm{m}^{-3}\right)\end{array}$ & $\begin{array}{c}D \theta / d t \\
\left(\mathrm{~K} \mathrm{~h}^{-1}\right)\end{array}$ & $\begin{array}{c}D q / d t \\
\left(\mathrm{~g} \mathrm{~kg}^{-1} \mathrm{~h}^{-1}\right)\end{array}$ & $\begin{array}{c}T_{\mathrm{LCL}} \\
(\mathrm{K})\end{array}$ & $\begin{array}{c}\text { Total } \theta_{e} \\
\theta_{e} \\
(\mathrm{~K})\end{array}$ & $\begin{array}{c}D \theta_{e} / d t \\
\left.(\mathrm{~K} \mathrm{~h})^{-1}\right)\end{array}$ & $\begin{array}{c}\text { streamge along } \\
(\mathrm{K})\end{array}$ \\
\hline Streamline
\end{tabular}




\section{REFERENCES}

Anthes, R. A., and S. Chang, 1978: Response of the hurricane boundary layer to changes of sea surface temperature in a numerical model. J. Atmos. Sci., 35, 1240-1255, https://doi.org/ 10.1175/1520-0469(1978)035<1240:ROTHBL>2.0.CO;2.

Barnes, G. M., and M. D. Powell, 1995: Evolution of the inflow boundary layer of Hurricane Gilbert (1988). Mon. Wea. Rev., 123, 2348-2368, https://doi.org/10.1175/1520-0493(1995) $123<2348$ :EOTIBL $>2.0$.CO;2.

— tensification of Hurricane Lili (2002). Mon. Wea. Rev., 138, 1446-1458, https://doi.org/10.1175/2009MWR3145.1.

- and K. P. Dolling, 2013: The inflow to Tropical Cyclone Humberto (2001) as viewed with azimuth-height surfaces over three days. Mon. Wea. Rev., 141, 1324-1336, https://doi.org/ 10.1175/MWR-D-11-00348.1.

_ - E. J. Zipser, D. Jorgensen, and F. D. Marks, 1983: Mesoscale and convective structure of a hurricane rainband. J. Atmos. Sci., 40, 2125-2137, https://doi.org/10.1175/1520-0469(1983) $040<2125$ :MACSOA $>2.0 . \mathrm{CO} ; 2$.

Black, M. L., J. F. Gamache, F. D. Marks, C. E. Samsury, and H. E. Willoughby, 2002: Eastern Pacific Hurricanes Jimena of 1991 and Olivia of 1994: The effect of vertical shear on structure and intensity. Mon. Wea. Rev., 130, 2291-2312, https://doi.org/ 10.1175/1520-0493(2002)130<2291:EPHJOA > 2.0.CO;2.

Black, R. A., H. B. Bluestein, and M. L. Black, 1994: Unusually strong vertical motions in a Caribbean hurricane. Mon. Wea. Rev., 122, 2722-2739, https://doi.org/10.1175/1520-0493(1994) $122<2722$ :USVMIA $>2.0 . \mathrm{CO} ; 2$

Bolton, D., 1980: The computation of equivalent potential temperature. Mon. Wea. Rev., 108, 1046-1053, https://doi.org/ 10.1175/1520-0493(1980)108<1046:TCOEPT>2.0.CO;2.

Braun, S. A., and Coauthors, 2013: NASA's Genesis and Rapid Intensification Processes (GRIP) Field Experiment. Bull. Amer. Meteor. Soc., 94, 345-363, https://doi.org/10.1175/ BAMS-D-11-00232.1.

Brown, J. M., 1979: Mesoscale unsaturated downdrafts driven by rainfall evaporation: A numerical study. J. Atmos. Sci., 36 , 313-338, https://doi.org/10.1175/1520-0469(1979)036<0313: MUDDBR $>2.0 . \mathrm{CO} ; 2$.

Chandrasekhar, S., 1961: Hydrodynamic and Hydromagnetic Stability. Clarendon Press, $652 \mathrm{pp}$.

Cione, J. J., P. G. Black, and S. H. Houston, 2000: Surface observations in the hurricane environment. Mon. Wea. Rev., 128, 1550-1561, https://doi.org/10.1175/1520-0493(2000)128<1550: SOITHE $>2.0 . \mathrm{CO} ; 2$

_ E. A. Kalina, J. A. Zhang, and E. W. Uhlhorn, 2013: Observations of air-sea interaction and intensity change in hurricanes. Mon. Wea. Rev., 141, 2368-2382, https://doi.org/ 10.1175/MWR-D-12-00070.1.

Corbosiero, K. L., and J. Molinari, 2002: The effects of vertical wind shear on the distribution of convection in tropical cyclones. Mon. Wea. Rev., 130, 2110-2123, https://doi.org/ 10.1175/1520-0493(2002)130<2110:TEOVWS>2.0.CO;2.

— , and - 2003: The relationship between storm motion, vertical wind shear, and convective asymmetries in tropical cyclones. J. Atmos. Sci., 60, 366-376, https://doi.org/10.1175/ 1520-0469(2003)060<0366:TRBSMV>2.0.CO;2.

Cram, T. A., J. Persing, M. T. Montgomery, and S. A. Braun, 2007: A Lagrangian trajectory view on transport and mixing processes between the eye, eyewall, and environment using a high-resolution simulation of Hurricane Bonnie
(1998). J. Atmos. Sci., 64, 1835-1856, https://doi.org/10.1175/ JAS3921.1.

DeHart, J. C., R. A. Houze, and R. F. Rogers, 2014: Quadrant distribution of tropical cyclone inner-core kinematics in relation to environmental shear. J. Atmos. Sci., 71, 2713-2732, https://doi.org/10.1175/JAS-D-13-0298.1.

DeMaria, M., 1996: The effect of vertical shear on tropical cyclone intensity change. J. Atmos. Sci., 53, 2076-2088, https://doi.org/ 10.1175/1520-0469(1996)053<2076:TEOVSO > 2.0.CO;2.

_ , and J. Kaplan, 1999: An updated Statistical Hurricane Intensity Prediction Scheme (SHIPS) for the Atlantic and eastern North Pacific basins. Wea. Forecasting, 14, 326-337, https://doi.org/10.1175/1520-0434(1999)014<0326:AUSHIP>2.0. $\mathrm{CO} ; 2$.

Didlake, A. C., and R. A. Houze, 2009: Convective-scale downdrafts in the principal rainband of Hurricane Katrina (2005). Mon. Wea. Rev., 137, 3269-3293, https://doi.org/10.1175/ 2009MWR2827.1.

Dolling, K. P., and G. M. Barnes, 2012: The creation of a high equivalent potential temperature reservoir in Tropical Storm Humberto (2001) and its possible role in storm deepening. Mon. Wea. Rev., 140, 492-505, https://doi.org/ 10.1175/MWR-D-11-00068.1.

— and - 2014: The evolution of Hurricane Humberto (2001). J. Atmos. Sci., 71, 1276-1291, https://doi.org/10.1175/ JAS-D-13-0164.1.

Eastin, M. D., W. M. Gray, and P. G. Black, 2005a: Buoyancy of convective vertical motions in the inner core of intense hurricanes. Part I: General statistics. Mon. Wea. Rev., 133, 188208, https://doi.org/10.1175/MWR-2848.1.

,-- , and $-2005 \mathrm{~b}$ : Buoyancy of convective vertical motions in the inner core of intense hurricanes. Part II: Case studies. Mon. Wea. Rev., 133, 209-227, https://doi.org/10.1175/ MWR-2849.1.

, T. L. Gardner, M. C. Link, and K. C. Smith, 2012: Surface cold pools in the outer rainbands of Tropical Storm Hanna (2008) near landfall. Mon. Wea. Rev., 140, 471-491, https:// doi.org/10.1175/MWR-D-11-00099.1.

Emanuel, K. A., 1986: An air-sea interaction theory for tropical cyclones. Part I: Steady-state maintenance. J. Atmos. Sci., 43, 585-605, https://doi.org/10.1175/1520-0469(1986)043<0585: AASITF $>2.0 . \mathrm{CO} ; 2$.

- 1988: The maximum intensity of hurricanes. J. Atmos. Sci., 45, 1143-1155, https://doi.org/10.1175/1520-0469(1988)045<1143: $\mathrm{TMIOH}>2.0 . \mathrm{CO} ; 2$.

Etling, D., and R. A. Brown, 1993: Roll vortices in the planetary boundary layer: A review. Bound.-Layer Meteor., 65, 215-248, https://doi.org/10.1007/BF00705527.

Frank, W. M., and E. A. Ritchie, 2001: Effects of vertical wind shear on the intensity and structure of numerically simulated hurricanes. Mon. Wea. Rev., 129, 2249-2269, https://doi.org/ 10.1175/1520-0493(2001)129<2249:EOVWSO > 2.0.CO;2.

Gamache, J. F., 1997: Evaluation of a fully three-dimensional variational Doppler analysis technique. Preprints, 28th Conf. on Radar Meteorology, Austin, TX, Amer. Meteor. Soc., 422-423.

Hock, T. F., and J. L. Franklin, 1999: The NCAR GPS dropwindsonde. Bull. Amer. Meteor. Soc., 80, 407-420, https://doi.org/ 10.1175/1520-0477(1999)080<0407:TNGD>2.0.CO;2.

Hookings, G. A., 1965: Precipitation-maintained downdrafts. J. Appl. Meteor., 4, 190-195, https://doi.org/10.1175/1520-0450 (1965)004<0190:PMD>2.0.CO;2.

Jaimes, B., L. K. Shay, and E. W. Uhlhorn, 2015: Enthalpy and momentum fluxes during Hurricane Earl relative to underlying 
ocean features. Mon. Wea. Rev., 143, 111-131, https://doi.org/ 10.1175/MWR-D-13-00277.1.

$[$, _ $—$, and J. K. Brewster, 2016: Observed air-sea interactions in Tropical Cyclone Isaac over loop current mesoscale eddy features. Dyn. Atmos. Oceans, 76, 306-324, https://doi.org/ 10.1016/j.dynatmoce.2016.03.001.

Kepert, J. D., 2006a: Observed boundary layer wind structure and balance in the hurricane core. Part I: Hurricane Georges. J. Atmos. Sci., 63, 2169-2193, https://doi.org/10.1175/ JAS3745.1.

_, 2006b: Observed boundary layer wind structure and balance in the hurricane core. Part II: Hurricane Mitch. J. Atmos. Sci., 63, 2194-2211, https://doi.org/10.1175/JAS3746.1.

— J. J. Schwendike, and H. Ramsay, 2016: Why is the tropical cyclone boundary layer not "well mixed"? J. Atmos. Sci., 73, 957-973, https://doi.org/10.1175/JAS-D-15-0216.1.

Klotz, B. W., and E. W. Uhlhorn, 2014: Improved stepped frequency microwave radiometer tropical cyclone surface winds in heavy precipitation. J. Atmos. Oceanic Technol., 31, 23922408, https://doi.org/10.1175/JTECH-D-14-00028.1.

_ , and H. Jiang, 2017: Examination of surface wind asymmetries in tropical cyclones. Part I: General structure and wind shear impacts. Mon. Wea. Rev., 145, 3989-4009, https://doi.org/ 10.1175/MWR-D-17-0019.1.

Knupp, K. R., and W. R. Cotton, 1985: Convective cloud downdraft structure: An interpretive survey. Rev. Geophys., 23, 183-215, https://doi.org/10.1029/RG023i002p00183.

Mariano, A. J., and O. B. Brown, 1992: Efficient objective analysis of dynamically heterogeneous and nonstationary fields via the parameter matrix. Deep-Sea Res., 39, 1255-1271, https:// doi.org/10.1016/0198-0149(92)90068-5.

Meyers, P. C., L. K. Shay, and J. K. Brewster, 2014: The development of the systematically merged Atlantic regional temperature and salinity climatology for hurricane intensity forecasting. J. Atmos. Oceanic Technol., 31, 131-149, https:// doi.org/10.1175/JTECH-D-13-00100.1.

Miles, J., 1961: On the stability of heterogeneous shear flows. J. Fluid Mech., 10, 496-508, https://doi.org/10.1017/ S0022112061000305.

Molinari, J., J. Frank, and D. Vollaro, 2013: Convective bursts, downdraft cooling, and boundary layer recovery in a sheared tropical storm. Mon. Wea. Rev., 141, 1048-1060, https:// doi.org/10.1175/MWR-D-12-00135.1.

Montgomery, M. T., J. Zhang, and R. K. Smith, 2014: An analysis of the observed low-level structure of rapidly intensifying and mature Hurricane Earl (2010). Quart. J. Roy. Meteor. Soc., 140, 2132-2146, https://doi.org/10.1002/qj.2283.

Nguyen, L. T., R. F. Rogers, and P. D. Reasor, 2017: Thermodynamic and kinematic influences on precipitation symmetry in sheared tropical cyclones: Bertha and Cristobal (2014). Mon. Wea. Rev., 145, 4423-4446, https://doi.org/10.1175/ MWR-D-17-0073.1.

Powell, M. D., 1990: Boundary layer structure and dynamics in outer hurricane rainbands. Part II: Downdraft modification and mixed layer recovery. Mon. Wea. Rev., 118, 918-938, https://doi.org/10.1175/1520-0493(1990)118<0918:BLSADI >2.0. $\mathrm{CO} ; 2$.

Reasor, P. D., and M. D. Eastin, 2012: Rapidly intensifying Hurricane Guillermo (1997). Part II: Resilience in shear. Mon. Wea. Rev., 140, 425-444, https://doi.org/10.1175/MWR-D-1100080.1.

—, M. T. Montgomery, F. D. Marks Jr., and J. F. Gamache, 2000: Low-wavenumber structure and evolution of the hurricane inner core observed by airborne dual-Doppler radar. Mon. Wea. Rev., 128, 1653-1680, https://doi.org/10.1175/1520-0493(2000) 128<1653:LWSAEO $>2$ 2.0.CO;2.

—, M. D. Eastin, and J. F. Gamache, 2009: Rapidly intensifying Hurricane Guillermo (1997). Part I: Low-wavenumber structure and evolution. Mon. Wea. Rev., 137, 603-631, https:// doi.org/10.1175/2008MWR2487.1.

— R. F. Rogers, and S. Lorsolo, 2013: Environmental flow impacts on tropical cyclone structure diagnosed from airborne Doppler radar composites. Mon. Wea. Rev., 141, 2949-2969, https://doi.org/10.1175/MWR-D-12-00334.1.

Riemer, M., M. T. Montgomery, and M. E. Nicholls, 2010: A new paradigm for intensity modification of tropical cyclones: Thermodynamic impact of vertical wind shear on the inflow layer. Atmos. Chem. Phys., 10, 3163-3188, https://doi.org/ 10.5194/acp-10-3163-2010.

Rogers, R. F., S. Lorsolo, P. D. Reasor, J. Gamache, and F. D. Marks Jr., 2012: Multiscale analysis of tropical cyclone kinematic structure from airborne Doppler radar composites. Mon. Wea. Rev., 140, 77-99, https://doi.org/10.1175/MWR-D10-05075.1.

_ _ P. D. Reasor, and S. Lorsolo, 2013a: Airborne Doppler observations of the inner-core structural differences between intensifying and steady-state tropical cyclones. Mon. Wea. Rev., 141, 2970-2991, https://doi.org/10.1175/MWR-D-1200357.1.

—_, and Coauthors, 2013b: NOAA's Hurricane Intensity Forecasting Experiment: A progress report. Bull. Amer. Meteor. Soc., 94, 859-882, https://doi.org/10.1175/BAMSD-12-00089.1.

— , P. Reasor, and J. Zhang, 2015: Multiscale structure and evolution of Hurricane Earl (2010) during rapid intensification. Mon. Wea. Rev., 143, 536-562, https://doi.org/10.1175/ MWR-D-14-00175.1.

_ J. Zhang, J. Zawislak, H. Jiang, G. R. Alvey III, E. J. Zipser, and S. N. Stevenson, 2016: Observations of the structure and evolution of Hurricane Edouard (2014) during intensity change. Part II: Kinematic structure and the distribution of deep convection. Mon. Wea. Rev., 144, 3355-3376, https:// doi.org/10.1175/MWR-D-16-0017.1.

Shay, L. K., and E. Uhlhorn, 2008: Loop Current response to Hurricanes Isidore and Lili. Mon. Wea. Rev., 136, 3248-3274, https://doi.org/10.1175/2007MWR2169.1.

—_, G. J. Goni, and P. G. Black, 2000: Effects of a warm oceanic feature on Hurricane Opal. Mon. Wea. Rev., 128, 1366-1383, https://doi.org/10.1175/1520-0493(2000)128<1366: EOAWOF $>2.0 . \mathrm{CO} ; 2$.

Stern, D. P., G. H. Bryan, and S. D. Aberson, 2016: Extreme lowlevel updrafts and wind speeds measured by dropsondes in tropical cyclones. Mon. Wea. Rev., 144, 2177-2204, https:// doi.org/10.1175/MWR-D-15-0313.1.

Stevenson, S. N., K. L. Corbosiero, and J. Molinari, 2014: The convective evolution and rapid intensification of Hurricane Earl (2010). Mon. Wea. Rev., 142, 4364-4380, https://doi.org/ 10.1175/MWR-D-14-00078.1.

Susca-Lopata, G., J. Zawislak, E. J. Zipser, and R. F. Rogers, 2015: The role of observed environmental conditions and precipitation evolution in the rapid intensification of Hurricane Earl (2010). Mon. Wea. Rev., 143, 2207-2223, https://doi.org/ 10.1175/MWR-D-14-00283.1.

Tang, B., and K. Emanuel, 2010: Midlevel ventilation's constraint on tropical cyclone intensity. J. Atmos. Sci., 67, 1817-1830, https://doi.org/10.1175/2010JAS3318.1. 
_ and - 2012: Sensitivity of tropical cyclone intensity to ventilation in an axisymmetric model. J. Atmos. Sci., 69, 2394 2413, https://doi.org/10.1175/JAS-D-11-0232.1.

Wadler, J. B., R. F. Rogers, and P. D. Reasor, 2018: The relationship between spatial variations in the structure of convective bursts and tropical cyclone intensification as determined by airborne Doppler radar. Mon. Wea. Rev., 146, 761-780, https://doi.org/ 10.1175/MWR-D-17-0213.1.

Willoughby, H. E., and M. B. Chelmow, 1982: Objective determination of hurricane tracks from aircraft observations. Mon. Wea. Rev., 110, 1298-1305, https://doi.org/10.1175/15200493(1982)110<1298:ODOHTF $>2.0$. CO;2.

Young, G. S., D. A. R. Kristovich, M. R. Hjelmfelt, and R. C. Foster, 2002: Rolls, streets, waves, and more: A review of quasitwo-dimensional structures in the atmospheric boundary layer. Bull. Amer. Meteor. Soc., 83, 997-1002, https://doi.org/10.1175/ 1520-0477(2002)083<0997:RSWAMA $>2.3$.CO;2.

Zawislak, J., H. Jiang, G. Alvey, E. Zipser, R. Rogers, J. Zhang, and S. Stevenson, 2016: Observations of the structure and evolution of Hurricane Edouard (2014) during intensity change. Part I: Relationship between the thermodynamic structure and precipitation. Mon. Wea. Rev., 144, 3333-3354, https://doi.org/10.1175/MWR-D-16-0018.1.

Zhang, J. A., P. G. Black, J. R. French, and W. M. Drennan, 2008a: First direct measurements of enthalpy flux in the hurricane boundary layer: The CBLAST results. Geophys. Res. Lett., 35, L14813, https://doi.org/10.1029/2008GL034374.

, K. B. Katsaros, P. G. Black, S. Lehner, J. R. French, and W. M. Drennan, 2008b: Effects of roll vortices on turbulent fluxes in the hurricane boundary layer. Bound.-Layer Meteor., 128, 173-189, https://doi.org/10.1007/s10546-0089281-2.

, R. F. Rogers, D. S. Nolan, and F. D. Marks, 2011: On the characteristic height scales of the hurricane boundary layer. Mon. Wea. Rev., 139, 2523-2535, https://doi.org/10.1175/ MWR-D-10-05017.1.

— — - P. Reasor, E. Uhlhorn, and F. Marks, 2013: Asymmetric hurricane boundary layer structure from dropsonde composites in relation to the environmental vertical wind shear. Mon. Wea. Rev., 141, 3968-3984, https://doi.org/ 10.1175/MWR-D-12-00335.1.

_ J. J. Cione, E. A. Kalina, E. W. Uhlhorn, T. Hock, and J. A. Smith, 2017: Observations of infrared sea surface temperature and air-sea interaction in Hurricane Edouard (2014) using GPS dropsondes. J. Atmos. Oceanic Technol., 34, 13331349, https://doi.org/10.1175/JTECH-D-16-0211.1.

Zipser, E. J., 1977: Mesoscale and convective-scale downdrafts as distinct components of squall-line structure. Mon. Wea. Rev., 105, 1568-1589, https://doi.org/10.1175/1520-0493(1977) $105<1568$ :MACDAD $>2.0 . \mathrm{CO} ; 2$ 